\title{
Metabolite and Isotopomer Balancing in the Analysis of Metabolic Cycles: I. Theory
}

\author{
Maria I. Klapa, ${ }^{1}$ Sung M. Park, ${ }^{1}$ Anthony J. Sinskey, ${ }^{2}$ \\ Gregory Stephanopoulos ${ }^{1}$ \\ ${ }^{1}$ Department of Chemical Engineering, Massachusetts Institute \\ of Technology \\ ${ }^{2}$ Department of Biology, Massachusetts Institute of Technology, \\ Cambridge, Massachusetts 02139
}

Received 19 December 1997; accepted 24 July 1998

\begin{abstract}
Proper analysis of label distribution in metabolic pathway intermediates is critical for correct interpretation of experimental data and strategic experimental design. While, for example, ${ }^{13} \mathrm{C}$ nuclear magnetic resonance (NMR) spectroscopy is usually limited to the measurement of degrees of ${ }^{13} \mathrm{C}$ enrichment, more information about metabolic fluxes can be extracted from the fine structure of NMR spectra, or molecular weight distributions of isotopomers of metabolic intermediates (measured by gas chromatography-mass spectrometry). For this purpose, rigorous accounting for the contribution of all pathways to label distribution is required, especially contributions resulting from multiple turns of metabolic cycles. In this paper we present a mathematical model developed to analyze isotopomer distributions of tricarboxylic acid cycle (TCA) intermediates following the administration of ${ }^{13} \mathrm{C}$ (or ${ }^{14} \mathrm{C}$ ) labeled substrates. The theory presented provides the basis to analyze ${ }^{13} \mathrm{C} N \mathrm{NM}$ spectra and molecular weight distributions of metabolites. In a companion paper (Park et al., 1999), the theory is applied to the analysis of several cases of biological significance. (C) 1999 John Wiley \& Sons, Inc. Biotechnol Bioeng 62: 375-391, 1999.
\end{abstract}

Keywords: isotopomer analysis; metabolic flux analysis; TCA cycle; ${ }^{13}$ C NMR; GC-MS

\section{INTRODUCTION}

Applications of stable isotopes in metabolic research have increased in the past decade. A vast amount of information about metabolic networks has been obtained through the administration of isotopically labeled substrates. The stable isotope ${ }^{13} \mathrm{C}$ has been used as a tracer to determine substrate oxidation rates and to develop clinical tests for rapid discrimination of digestive and metabolic disorders in glycolytic and gluconeogenic pathways. Breath tests in which samples of exhaled air are collected and analyzed following

Correspondence to: G. Stephanopoulos

Contract grant sponsors: National Science Foundation; Department of Energy BES

Contract grant numbers: BCS-9311509; DOE BES DE-FG02-94ER 14487 oral and parenteral administration of ${ }^{13} \mathrm{C}$ or ${ }^{14} \mathrm{C}$ labeled substrate have proven effective for measuring glucose utilization (Lacroix et al., 1973), fat absorption (Hofmann and Lauterburg, 1977; Watkins et al., 1982; Turner et al., 1987), for assessing liver (Schneider et al., 1978; Kurumaya et al., 1988) and pancreatic function (Solomons et al., 1977; Watkins et al., 1977), and for diagnosing Helicobacter pyrori infection (Marshall and Surveyor, 1988; Graham et al., 1988; Ormand et al., 1990; Novis et al., 1991) which is associated with gastric and peptic ulcer disease. Kassel et al. (1989) proposed the measurement of [U- $\left.{ }^{13} \mathrm{C}\right]$ glucose conversion into other metabolites as a diagnostic tool of differentiating enzyme defects associated with congenital lactic acidosis. Kalderon et al. (1989a,b) and Gopher et al. (1990) suggested the administration of labeled glucose or fructose followed by analysis of plasma glucose using a combination of gas chromatography-mass spectrometry (GC-MS) and ${ }^{13} \mathrm{C}$ nuclear magnetic resonance spectroscopy $\left({ }^{13} \mathrm{C} \mathrm{NMR}\right)$ as a simple noninvasive diagnostic tool for detecting glycolytic and gluconeogenic disease, such as glycogen storage disease type I and type III, and fructose intolerance. Magnusson et al. (1991) proposed the use of $\left[3-{ }^{14} \mathrm{C}\right]$ lactate in conjunction with phenylacetate as a means of following noninvasively the metabolism of the tricarboxylic acid (TCA) cycle in humans by analyzing the labeling pattern of phenylacetylglutamine in urine. Di Donato et al. (1993) modified the idea by administering $\left[3-{ }^{13} \mathrm{C}\right]$ lactate followed by an analysis with GC-MS and ${ }^{13} \mathrm{C}$ NMR. Their technique ("chemical biopsy") has emerged as a safe, noninvasive diagnostic tool for tracing metabolic pathways as well as for detecting enzymatic disorders.

${ }^{13} \mathrm{C}$ NMR spectroscopy has been used to study intermediary metabolism and its regulation through in vivo flux quantification in intact cells and isolated perfused organs (Shulman et al., 1979; Dickinson et al., 1983; Chance et al., 1983). Walsh and Koshland (1984) were able to determine the flux split ratio at the branch point of the tricarboxylic acid cycle and the glyoxylate shunt, based on the ${ }^{13} \mathrm{C} N \mathrm{NM}$ spectrum of intracellular glutamate in Escherichia coli. den 
Hollander et al. (1986) studied aerobic and anaerobic glycolysis in yeast Saccharomyces cerevisiae, whereas Walker and London (1987) studied the metabolic pathways leading to the biosynthesis of glutamate by Brevibacterium flavum. Using isotopically labeled acetate, Crawford et al. (1987) monitored acetate metabolism in a proline-overproducing strain of E c coli and Narbad et al. (1989) studied acetate and methanol metabolism of methylotrophic Pseudomonas strains. Sonntag et al. (1993) quantified the flux partitioning in the split pathway of lysine synthesis in Corynebacterium glutamicum by using ${ }^{13} \mathrm{C}-\mathrm{NMR}$ spectroscopy. Recently, Marx et al. (1996) used ${ }^{13} \mathrm{C}$ carbon enrichment analysis to study the central carbon metabolism of Corynebacterium glutamicum, whereas Szyperski et al. (1996) introduced the use of 2-D NMR in combination with the use of biosynthetic fractional ${ }^{13} \mathrm{C}$ labeling for the detection of metabolic fluxes.

Unfortunately, the lack of a rigorous mathematical framework to calculate label distributions in metabolic networks has often necessitated the introduction of simplified reaction schematics, often yielding erroneous conclusions (see Park et al. (1999)). The lack of appropriate analytical tools is especially problematic in the studies involving cyclic pathways such as the pentose phosphate pathway (PPP) and the TCA cycle where intermediates can reenter the cycle and produce different labeling patterns. Rigorous accounting of the isotopomer distributions can provide information of finer resolution about biochemical network structure.

This paper is an attempt to account rigorously for the contributions of all reactions to the labeling of metabolites involved in metabolic cycles after many turns of such cycles. A general method is provided for calculating isotopomer distributions and enrichment patterns in metabolic intermediates of the TCA cycle and glucose via the gluconeogenic pathway. In a companion paper (Park et al., 1999), the validity of our developed model is assessed by comparing theoretical predictions with experimental data reported in the literature. Furthermore, the types of error associated with improperly accounting for the label redistribution through multiple turns via the TCA cycle are fully discussed.

\section{PREVIOUS MODELING WORKS}

The first analysis of label distribution through the TCA cycle and gluconeogenesis was made by Weinman et al. (1957) who studied the conversion of fatty acids to carbohydrate. Using a convergent geometric series, they derived expressions for the distribution of label in individual carbons of glucose and $\mathrm{CO}_{2}$ resulting from the use of labeled acetate, as a function of the relative fluxes via citrate synthase and pyruvate carboxylase. Though correct, the algebra was tedious, making applications to more complex systems extremely difficult. The same idea was extended by Exton and Park (1967) who investigated the label distribution of pyruvate. A more convenient procedure was proposed by
Katz and Grunnet (1979), who developed input-output equations for each carbon of intermediary metabolites and applied the methodology to the study of the PPP and TCA cycle intermediates. This method can be extended to other systems with many variables. However, all of these methods calculated only carbon isotope enrichments at specific carbon positions of the metabolites. As such, they did not provide information about isotopomers and the carbon label distribution in isotopomers of individual metabolites, and consequently failed to explain the multiplet structures observed in the ${ }^{13} \mathrm{C}$ NMR spectra and the molecular weight distribution of metabolites measured by GC-MS.

Chance et al. (1983) were the first to realize the importance of label scrambling via the TCA cycle and provided an elegant model for the evolution of ${ }^{13} \mathrm{C}$ enrichment of the TCA cycle intermediates. They developed a transient kinetic model for metabolite ${ }^{13} \mathrm{C}$ label enrichment by considering contributions from each isotopomer as distinct, individual species. This approach requires intensive measurements of metabolite concentrations and kinetic variables which limit its broader applicability. This problem is minimized in the modeling approach presented here which employs input-output balances for all biochemically feasible isotopomer species instead of individual carbons, under the assumption of a metabolic and isotopic steady state. Not only is the mathematics greatly simplified by this method but also fewer measurements are required for obtaining the same type of information.

Our work builds on that of Malloy et al. (1988), who employed a similar approach involving, however, all possible $\alpha$-ketoglutarate isotopomers. Our model deals only with the isotopomers of the TCA cycle intermediates, which get generated based on the assumed biochemistry (see Model Development). The model also accounts for the introduction of labeled $\mathrm{CO}_{2}$ through the anaplerotic carboxylating reactions. In addition, we provide useful extension of the modeling results that use the fine structure of NMR spectra and molecular weight distributions of selected isotopomers to predict the values of in vivo metabolic fluxes. Our focus is on the accurate determination of metabolic fluxes, using the maximum amount of information that can be obtained from combination of labeling techniques. It should be emphasized that our model is general and is not restricted to a particular structure of TCA cycle, or the TCA cycle alone. It can be applied accordingly to describe other network structures, as well as for different types of labeled substrates than those shown here. However, it is not always possible to derive an analytical solution, as in the case of the cyclic pathways presented in this paper.

\section{DESCRIPTION OF PATHWAYS}

We will demonstrate our modeling approach in the context of the metabolic pathways utilizing two types of gluconeogenic substrates: three-carbon $\left(\mathrm{C}_{3}\right)$ metabolites such as pyruvate and lactate and two-carbon $\left(\mathrm{C}_{2}\right)$ metabolites such as 


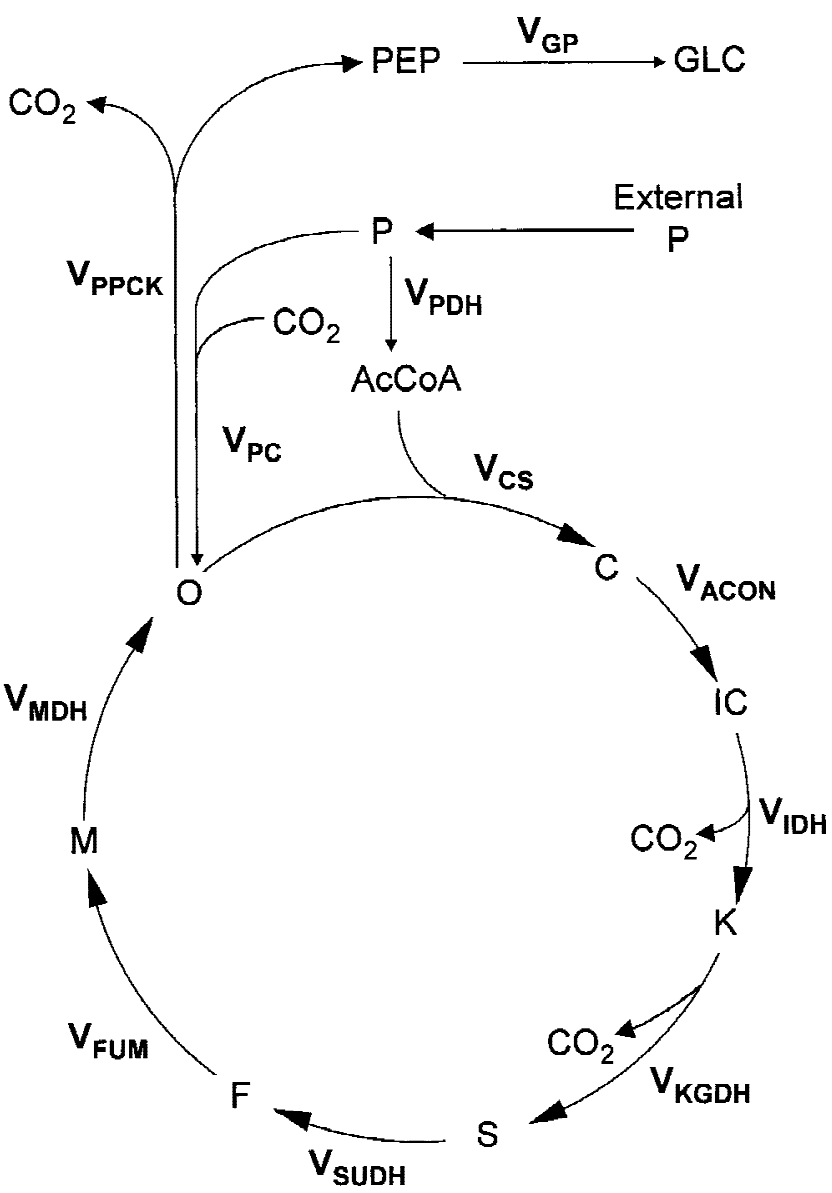

acetate and ethanol. Each of these substrates is metabolized via different pathways, and, depending on the extent of the pathway utilized, the resulting pattern of label distribution in the intermediates will be drastically different. Figure 1 shows the metabolic scheme of pyruvate utilization via the TCA cycle and gluconeogenic pathway commonly found in eukaryotic systems. We will assume that no phosphoenolpyruvate (PEP) is formed directly from pyruvate via PEP synthetase, but rather synthesized from oxaloacetate (OAA) via PEP carboxykinase. Pyruvate is converted to OAA by direct carboxylation and to acetyl-CoA by pyruvate dehydrogenase. AcCoA then condenses with OAA to form citrate that traverses the TCA cycle and eventually regenerates OAA. Finally, glucose can be formed from PEP via the reverse Embden-Meyerhof scheme of glycolysis or gluconeogenic pathway.

Figure 2 summarizes three possible models for acetate utilization. Model I depicts acetate utilization via the glyoxylate shunt (GS) pathway, active in many bacterial systems. The operation of this pathway is essential for growth on acetate as sole carbon source since it replenishes TCA cycle intermediates drained off for biosynthesis. Bacteria maintain a precise balance of carbon utilization for energetic and biosynthetic requirements by controlling the carbon flow at the isocitrate branchpoint. Isocitrate, when catalyzed by the action of isocitrate dehydrogenase and subsequently by the enzymes of the TCA cycle, will lead to the
Figure 1. Pyruvate utilization via the citric acid cycle and the gluconeogenic pathway. The abbreviations used in the subscript of the fluxes are: GP, gluconeogenic pathway; PDH, pyruvate dehydrogenase; CS, citrate synthase; ACON, aconitase; KGDH, $\alpha$-ketoglutarate dehydrogenase; SUDH, succinate dehydrogenase; FUM, fumarase; $\mathrm{MDH}$, malate dehydrogenase; PPCK, phosphoenolpyruvate carboxykinase; and PC, pyruvate carboxylase. The abbreviations for metabolites are: PEP, phosphoenolpyruvate; $\mathrm{P}$, pyruvate; AcCoA, acetyl $\mathrm{CoA}$; $\mathrm{C}$, citrate; IC, isocitrate; $\mathrm{K}, \alpha$-ketoglutarate; S, succinate; F, fumarate; $\mathrm{M}$, malate; $\mathrm{O}$, oxaloacetate; $\mathrm{CO}_{2}$, carbon dioxide; GLC, glucose. The operation of futile cycles such as "PEP $\rightarrow \mathrm{P} \rightarrow \mathrm{O} \rightarrow \mathrm{PEP}^{\prime}$ ' is assumed inactive. Other reactions for biosynthesis, such as glutamate-oxaloacetate transaminase and glutamate dehydrogenase, are ignored. production of NADH which is used for energy generation. Alternatively, isocitrate can be converted to succinate and glyoxylate by the action of isocitrate lyase, and glyoxylate condenses with acetyl-CoA to produce malate. Thus via the GS pathway, one molecule of OAA is formed from two molecules of acetate.

It has been established that in mammals acetate is utilized solely via conversion to acetyl-CoA which subsequently is catabolized in the TCA cycle (Fig. 2, Model II). However, in order to maintain a balanced steady state flow, a separate anaplerotic source for the synthesis of OAA must exist since some of the intermediates will be drained off the cycle to supply biosynthetic precursors such as glutamate and glutamine. We will consider two scenarios for the replenishment of OAA in conjunction with the utilization of acetate: the first, depicted as Model II, is a generally accepted pathway in which acetate is utilized only via acetyl-CoA conversion by acetyl-CoA synthase. In this case, alternative metabolite sources exist that provide for OAA formation. The second scenario of OAA replenishment (Model III) is a hypothetical pathway in which OAA is derived directly from acetate. This can be accomplished by condensation of two acetyl-CoA molecules to form acetoacetate, that is, in turn decarboxylated to form lactate or pyruvate, which eventually becomes the source of OAA. The pathway leading to the synthesis of $\mathrm{C}_{3}$ metabolites such as lactate or pyruvate from acetoacetate is not clearly established. How- 


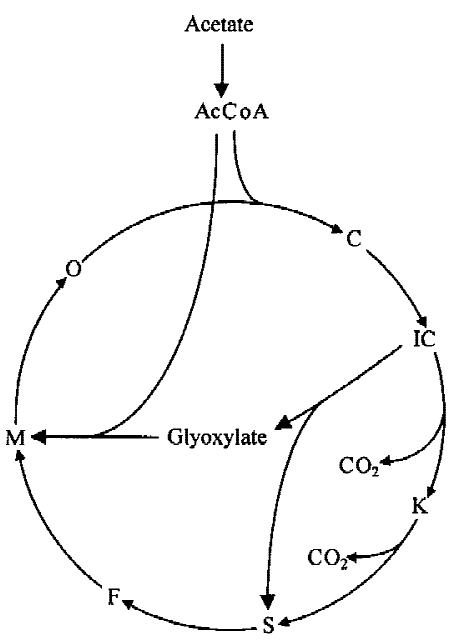

Model I

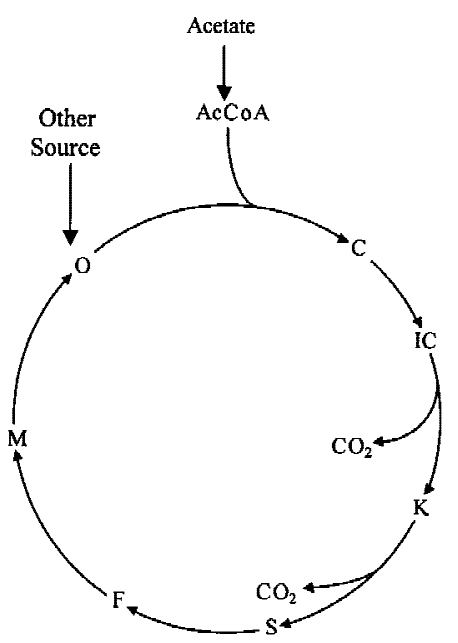

Model II

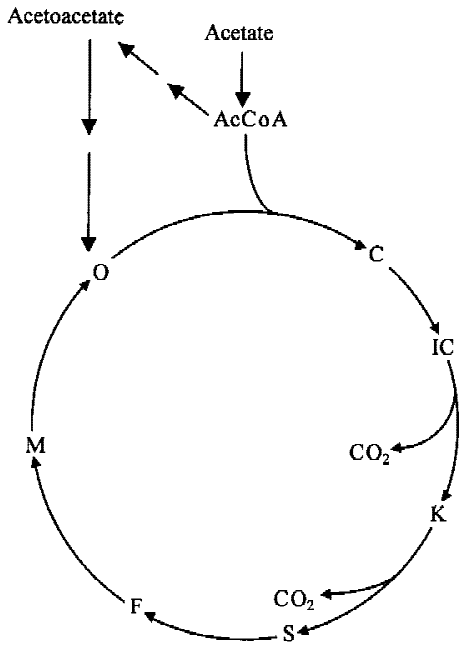

Model III

Figure 2. Three proposed models for acetate utilization. In Model I, acetate is utilized via the dual pathways: The TCA cycle and the glyoxylate shunt pathway. In Model II, acetate is utilized solely via the conversion to acetyl CoA which traverses the TCA cycle. Oxaloacetate is replenished from the other metabolites endogenously present. In Model III, acetate is converted to acetyl CoA and also becomes the source for oxaloacetate synthesis via the route of acetoacetate to lactate to pyruvate pathway. The operation of the Model III pathway is not yet clearly established.

ever, this hypothetical pathway is not entirely infeasible because there is evidence for the formation of 3-hydroxybutyrate from acetate in sheep (Annison et al., 1963), and formation of labeled acetoacetate from labeled acetate in rat liver (Desmoulin et al., 1985). The purpose of including Model III is to test if any of the labeling studies are consistent with Model III, for in this case, OAA entering the TCA cycle will be always labeled if the input acetate is labeled. The GS pathway is not found in mammalian systems.

\section{MODEL DEVELOPMENT}

The goal of this analysis is to provide the means for maximizing the amount of information that can be extracted from experiments with ${ }^{13} \mathrm{C}$ labeled substrates. To this end, one needs, first, to identify the types of isotopomers that arise in a pathway for a certain labeled substrate, and, second, to obtain expressions for the relative populations of these isotopomers as a function of metabolic fluxes. The degree of label enrichment at any carbon atom of any metabolite, isotopomer molecular weight distribution, and fine structure of NMR spectra can be subsequently derived from the isotopomer distributions. Consequently, all three kinds of measurements can, through the isotopomer balances, provide additional constraints on the metabolic fluxes, besides those imposed from the material balances. The combination of all those measurements involves a high degree of redundancy, necessary for the accurate determination of metabolic fluxes.

We shall illustrate the proposed methodology for the network of Fig. 1 with pyruvate $a \%(0 \leqslant a \leqslant 100)$ enriched at carbon 3 as substrate. The model can be similarly applied to describe network structures such as those of Section 3, as well as for different type of labeled substrate(s).

\section{Isotopomer Identification via Multiple Turns of the TCA Cycle}

Figure 3 shows the fate of ${ }^{13} \mathrm{C}$ label present in pyruvate $a \%$ enriched at carbon 3 after multiple turns through the TCA cycle. Starting with $a \%\left[3-{ }^{13} \mathrm{C}\right]$ pyruvate, $a \%$ of acetyl-CoA will be labeled at the C-2 position via the pyruvate dehydrogenase reaction. OAA derived from labeled pyruvate via pyruvate carboxylase reaction will be of the form $\mathrm{O}_{34}$ if the bicarbonate fixed is labeled with ${ }^{13} \mathrm{CO}_{2}$, and $\mathrm{O}_{3}$ if the bicarbonate fixed is unlabeled. OAA derived from unlabeled pyruvate via the anaplerotic reaction will be of the form $\mathrm{O}_{4}$ if the bicarbonate fixed is labeled with ${ }^{13} \mathrm{CO}_{2}$, and $\mathrm{O}$ if the bicarbonate fixed is unlabeled. Furthermore, it is assumed that the sequence of reverse reactions from OAA to fumarate is very rapid compared to the reactions of citrate synthase and PEP carboxykinase, and thus result in full symmetrical equilibration of carbon label between $\mathrm{C}-1$ and $\mathrm{C}-4$, and between C-2 and C-3 in OAA, succinate, malate, and fumarate (Chance et al., 1983; Malloy et al., 1988). This assumption results in an equal concentration of $\mathrm{O}_{34}$ and $\mathrm{O}_{12}$ and of $\mathrm{O}_{3}$ and $\mathrm{O}_{2}$, as well as of $\mathrm{O}_{4}$ and $\mathrm{O}_{1}$.

Following the TCA cycle, $\mathrm{O}_{34}$ condensing with $\mathrm{Ac}_{2}$ will yield $\mathrm{C}_{124}, \mathrm{~K}_{124}, \mathrm{~S}_{13}, 1 / 2 \mathrm{~F}_{13}+1 / 2 \mathrm{~F}_{24}, 1 / 2 \mathrm{M}_{13}+1 / 2 \mathrm{M}_{24}$, and $1 / 2 \mathrm{O}_{13}+1 / 2 \mathrm{O}_{24} \cdot \mathrm{O}_{34}$ condensing with unlabeled Ac will yield $\mathrm{C}_{12}, \mathrm{~K}_{12}, \mathrm{~S}_{1}, 1 / 2 \mathrm{~F}_{1}+1 / 2 \mathrm{~F}_{4}, 1 / 2 \mathrm{M}_{1}+1 / 2 \mathrm{M}_{4}$, and $1 / 2 \mathrm{O}_{1}+1 / 2 \mathrm{O}_{4}$. Similarly, other input and regenerated OAA species can be followed until no new species are formed. Note that not all 


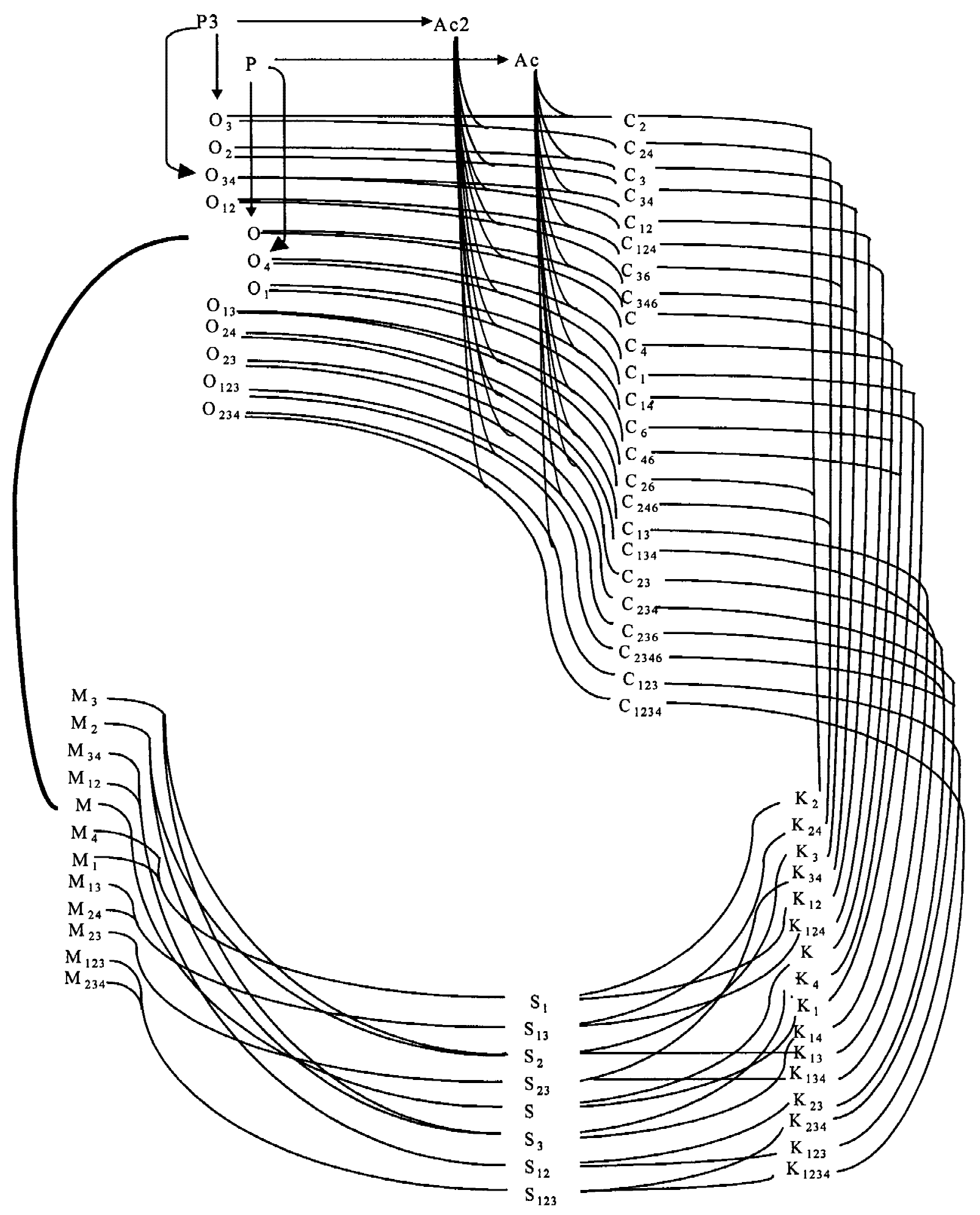

Figure 3. Schematic diagram of the sequential labeling of the carbons of intermediates via multiple turns of the TCA cycle for $a \%\left[3-{ }^{13} \mathrm{C}\right]$ pyruvate (where $a$ is a real number, $0 \leqslant a \leqslant 100)$. The diagram includes the two extreme cases of unlabeled and of $100 \%$ labeled pyruvate $\left(\mathrm{P}_{3}\right.$ or $\mathrm{P}$ will not be present, respectively). The simplifications possible in the latter case are shown in Fig. 4. Abbreviations are Ac, O, C, K, S, and Gx for acetyl CoA, oxaloacetate, citrate, $\alpha$-ketoglutarate, succinate, and glyoxylate, respectively. The numbers next to the metabolite symbol indicate the carbon position labeled by ${ }^{13} \mathrm{C}$. The line from the malate isotopomers to the oxaloacetate isotopomers shows a one-to-one relationship between the corresponding elements of the two sets of isotopomers $\left(\mathrm{M}_{3} \rightarrow \mathrm{O}_{3}\right.$ etc. $)$. 


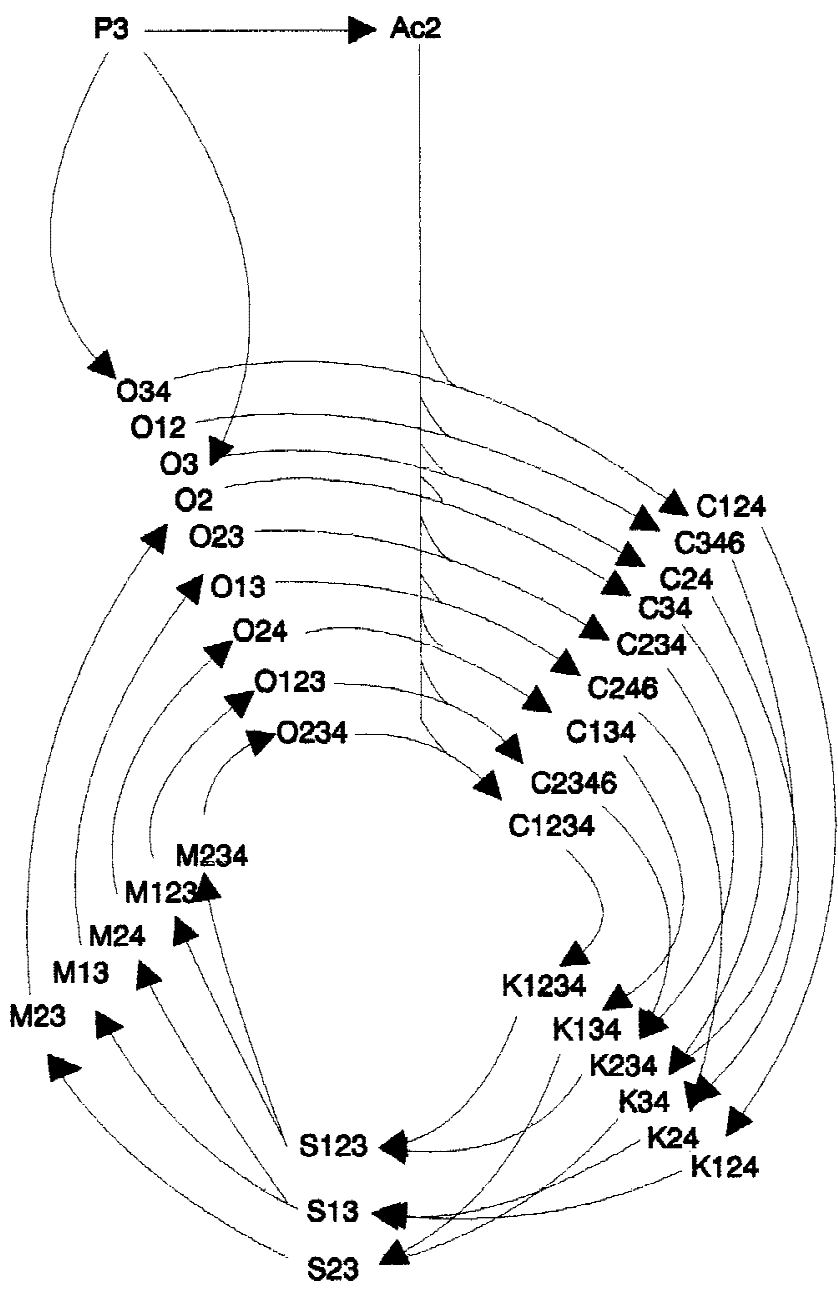

Figure 4. Schematic diagram of the sequential labeling of the carbons of intermediates via multiple turns of the TCA cycle using $100 \%\left[3-{ }^{13} \mathrm{C}\right]-$ pyruvate.

possible isotopomer species are generated. For example, there are $2^{5}=32 \alpha$-ketoglutarate species but only sixteen species are present in our model on the basis of the assumed biochemistry. Figure 4 shows the isotopomers for $100 \%$ $\left[3-{ }^{13} \mathrm{C}\right]$ pyruvate.

In a similar manner, the isotopomers for different-labeled substrates and for the structures of Section 3 can be obtained: Fig. 5 shows the isotopomers for $\left[2-{ }^{13} \mathrm{C}\right]$ pyruvate, Fig. 6 for $\left[1-{ }^{13} \mathrm{C}\right]$ pyruvate, Fig. 7 for $\left[2-{ }^{13} \mathrm{C}\right]$ acetate with Model I, Fig. 8 for $\left[2-{ }^{13} \mathrm{C}\right]$ acetate with Model II, Fig. 9 for $\left[2-{ }^{13} \mathrm{C}\right]$ acetate with Model III, Fig. 10 for $\left[1-{ }^{13} \mathrm{C}\right]$ acetate with Model I, Fig. 11 for $\left[1-{ }^{13} \mathrm{C}\right]$ acetate with Model II, and Fig. 12 for $\left[1-{ }^{13} \mathrm{C}\right]$ acetate with Model III. We note that the substrates in Figures 4-12 are 100\% enriched at the designated carbon atom.

Figure 13 shows the expected labeling pattern of glucose derived from OAA via the gluconeogenic pathway. It is noted that in deriving the labeling pattern of glucose, the pattern of OAA, not of $\alpha$-ketoglutarate, is needed and should be used. This simple point may seem superfluous, but ignoring it could lead to misinterpretations.

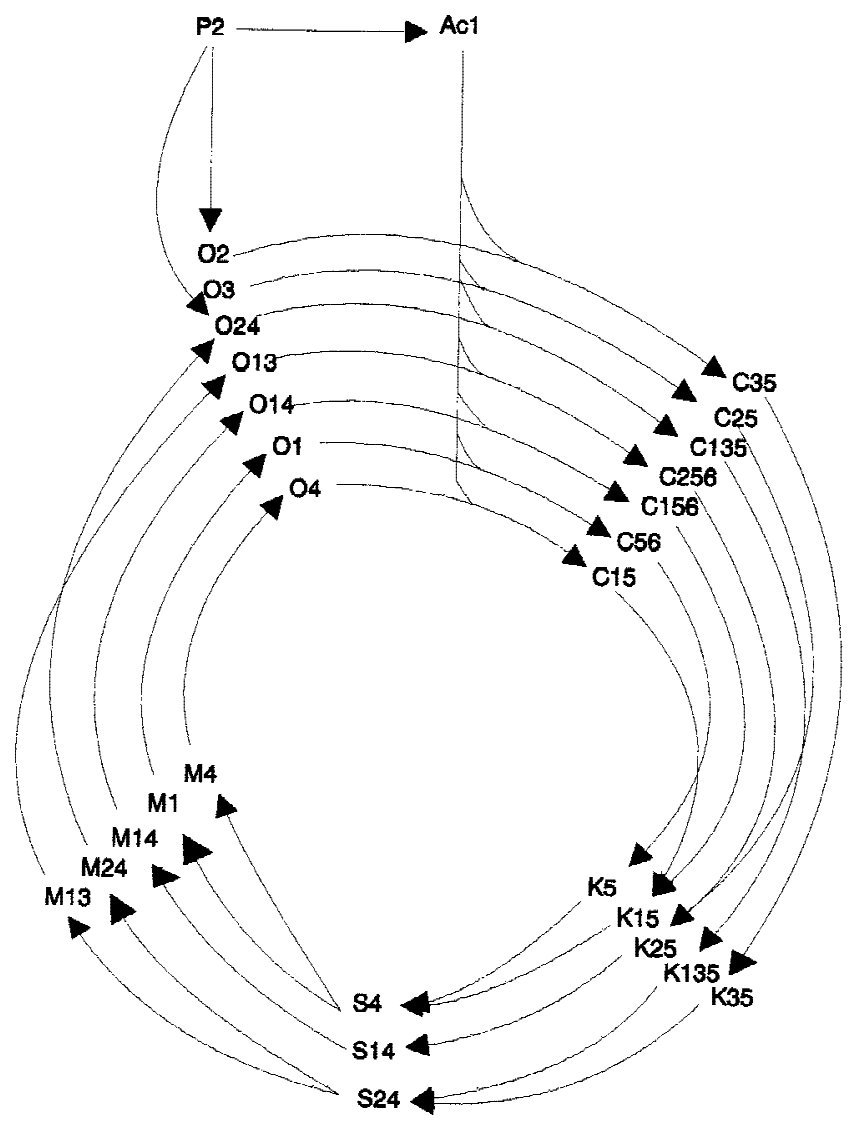

Figure 5. Schematic diagram of the sequential labeling of the carbons of intermediates via multiple turns of the TCA cycle using $100 \%\left[2-{ }^{13} \mathrm{C}\right]-$ pyruvate.

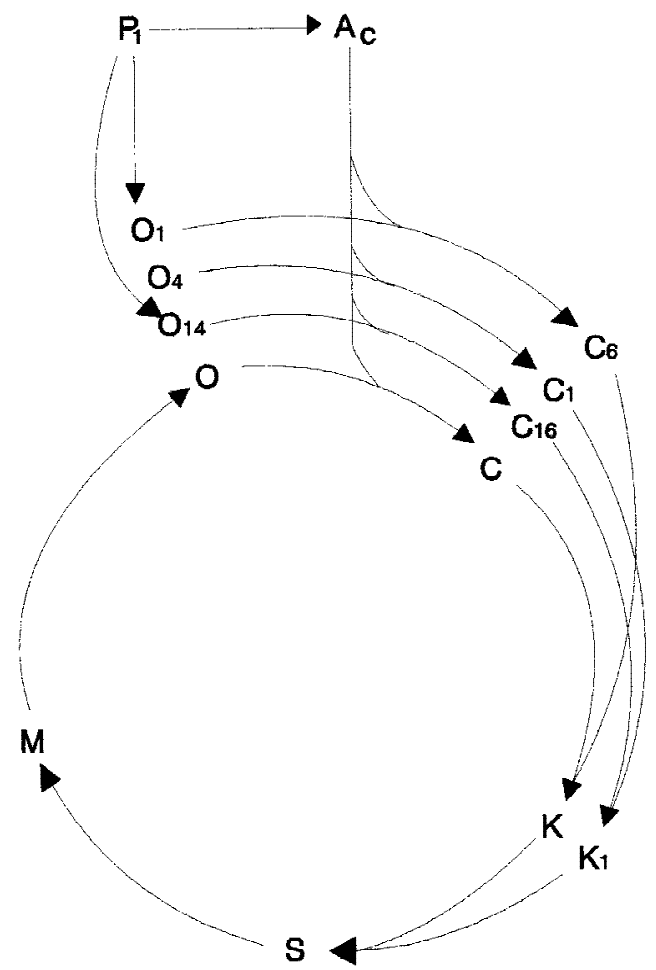

Figure 6. Schematic diagram of the sequential labeling of the carbons of intermediates via multiple turns of the TCA cycle using $100 \%\left[1-{ }^{13} \mathrm{C}\right]$-pyruvate. 


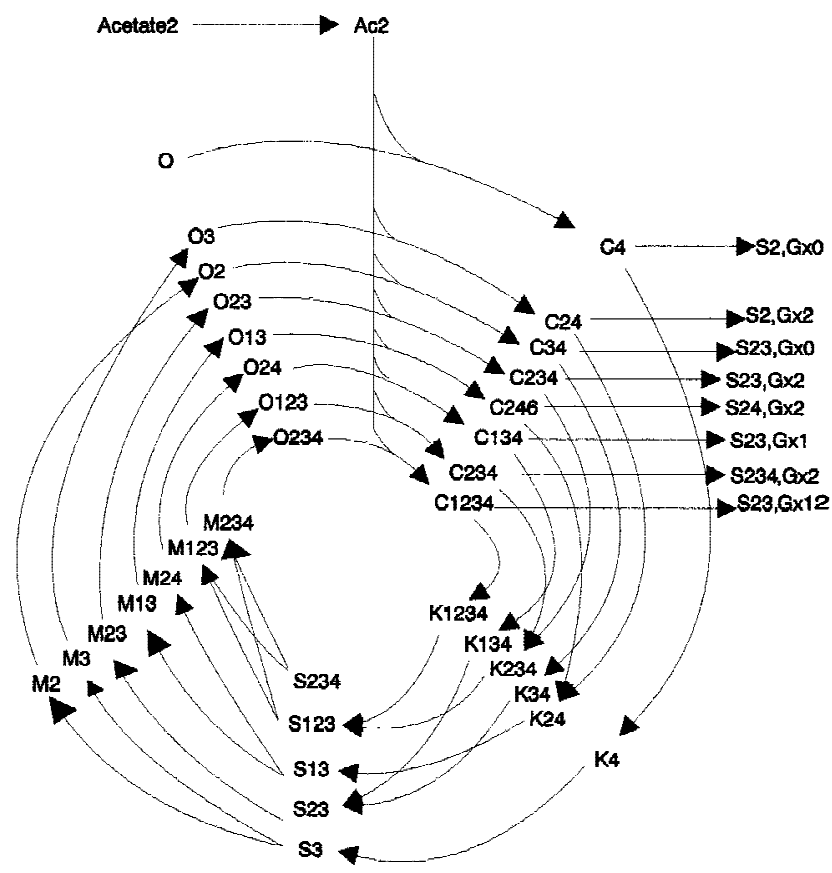

Figure 7. Schematic diagram of the sequential labeling of the carbons of intermediates via multiple turns of the TCA cycle and glyoxylate shunt pathway (Model I in Fig. 2) using 100\% $\left[2-{ }^{13} \mathrm{C}\right]$ acetate. The intermediates involved in the glyoxylate shunt are in exchange with those of the citric cycle.

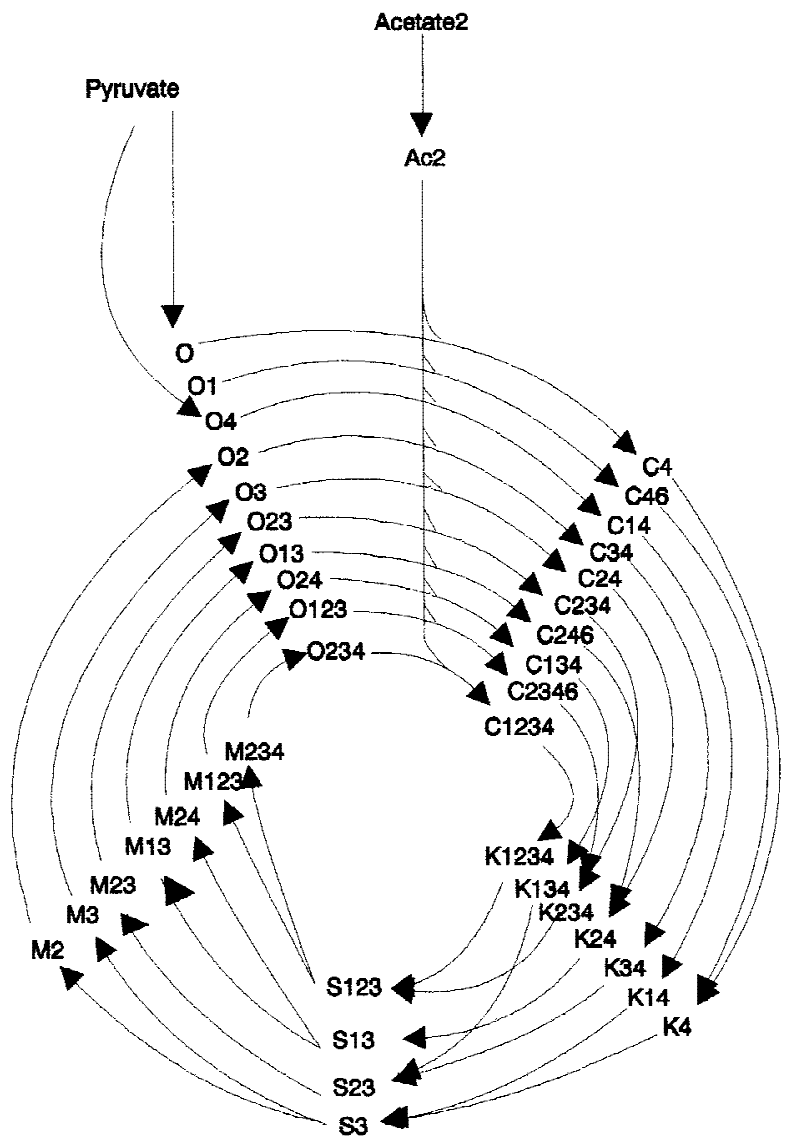

Figure 8. Schematic diagram of the sequential labeling of the carbons of intermediates via multiple turns of the TCA cycle and Model II pathway using $100 \%\left[2-{ }^{13} \mathrm{C}\right]$ acetate.

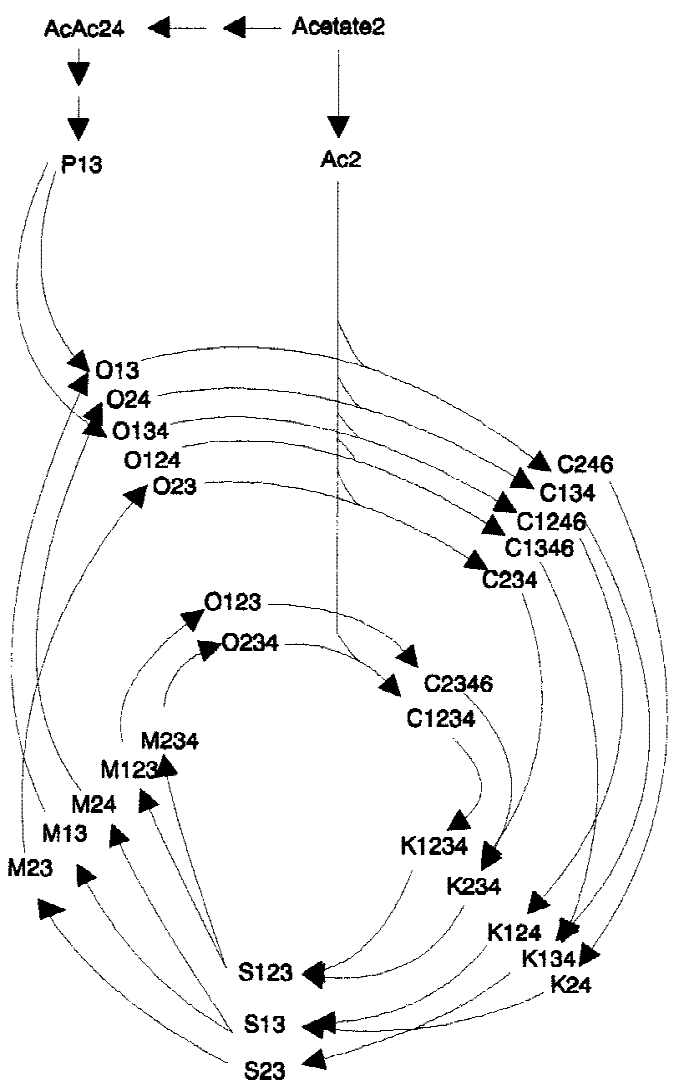

Figure 9. Schematic diagram of the sequential labeling of the carbons of intermediates via multiple turns of the citric acid cycle and Model III pathway using $100 \%\left[2-{ }^{13} \mathrm{C}\right]$ acetate.

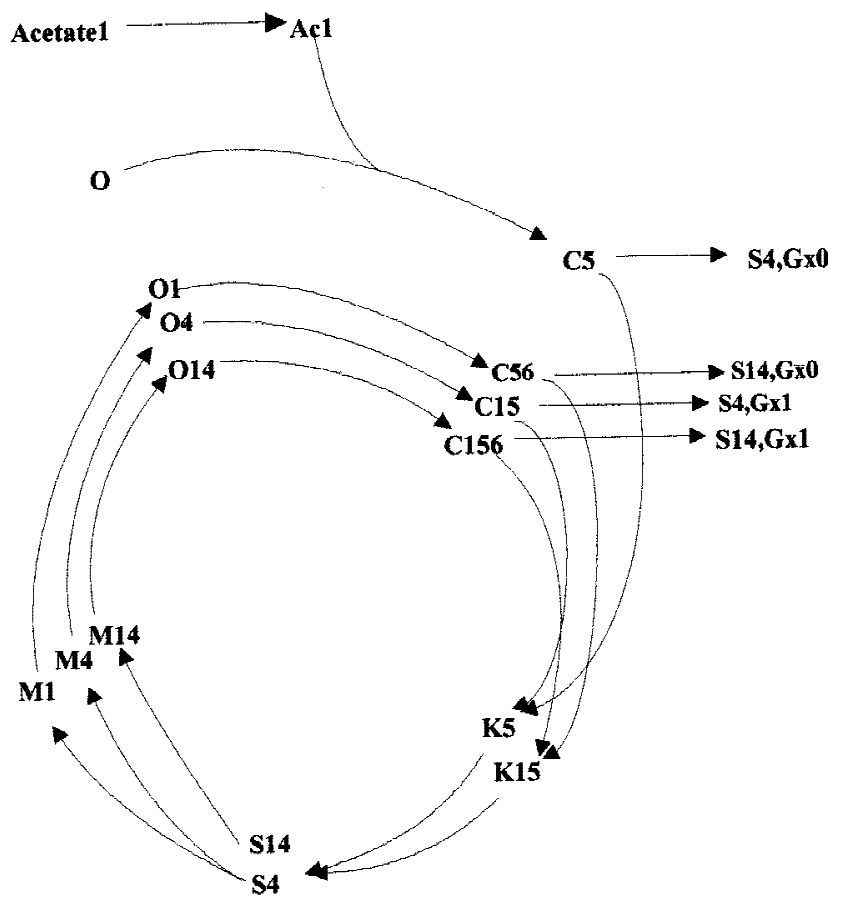

Figure 10. Schematic diagram of the sequential labeling of the carbons of intermediates via multiple turns of the TCA cycle and glyoxylate shunt pathway using $100 \%\left[1{ }^{13} \mathrm{C}\right]$ acetate. 


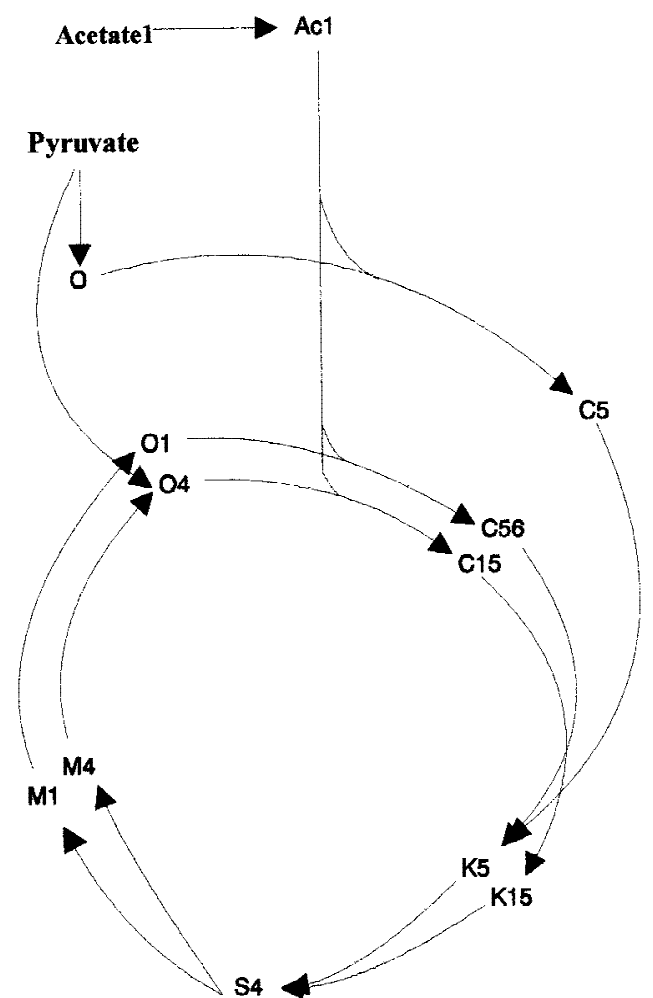

Figure 11. Schematic diagram of the sequential labeling of the carbons of intermediates via multiple turns of the TCA cycle and Model II pathway using $100 \%\left[1{ }^{13} \mathrm{C}\right]$ acetate.

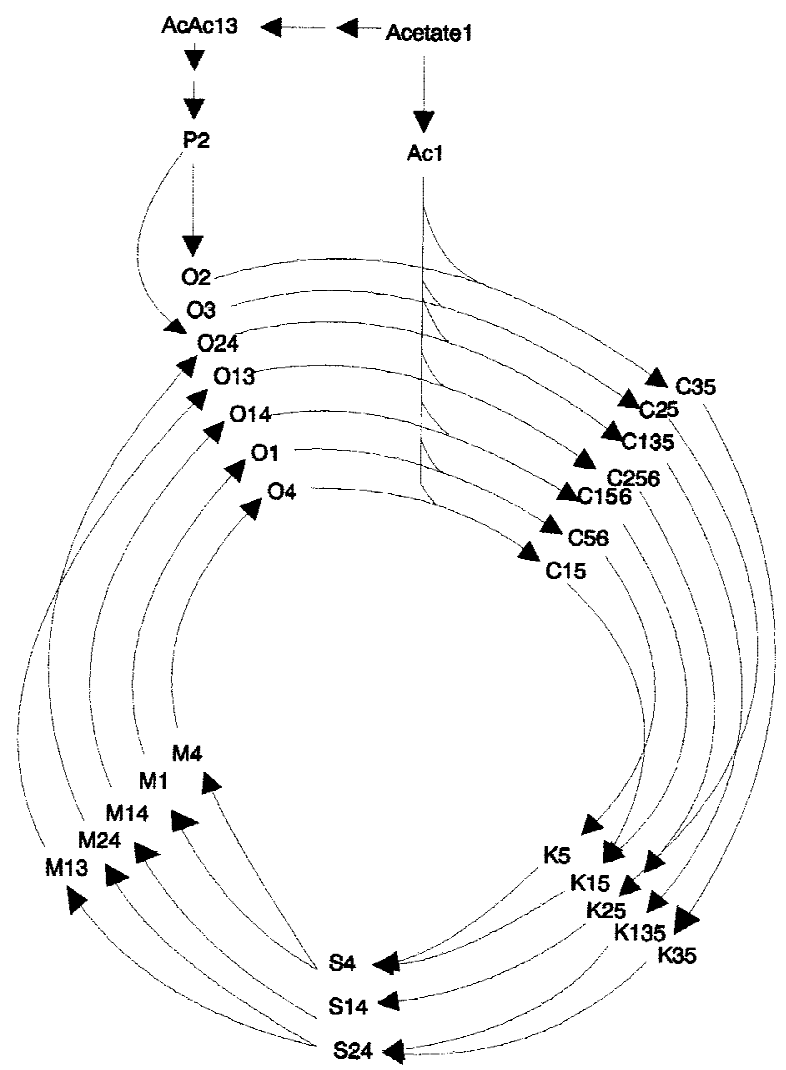

Figure 12. Schematic diagram of the sequential labeling of the carbons of intermediates via multiple turns of the TCA cycle and Model III pathway using $100 \%\left[1-{ }^{13} \mathrm{C}\right]$ acetate.

\section{Metabolite Mass Balances}

The mass balances for the metabolites depicted in the network of Fig. 1, are as follows:

$$
\begin{aligned}
& \frac{d}{d t}[\mathrm{AcCoa}]=V_{\mathrm{PDH}}-V_{\mathrm{CS}}, \\
& \frac{d}{d t}[\mathrm{C}]=V_{\mathrm{CS}}-V_{\mathrm{ACON}}, \\
& \frac{d}{d t}[\mathrm{IC}]=V_{\mathrm{ACON}}-V_{\mathrm{IDH}}, \\
& \frac{d}{d t}[\mathrm{~K}]=V_{\mathrm{IDH}}-V_{\mathrm{KGDH}}, \\
& \frac{d}{d t}[\mathrm{~S}]=V_{\mathrm{KGDH}}-V_{\mathrm{SUDH}}, \\
& \frac{d}{d t}[\mathrm{~F}]=V_{\mathrm{SUDH}}-V_{\mathrm{FUM}}, \\
& \frac{d}{d t}[\mathrm{M}]=V_{\mathrm{FUM}}-V_{\mathrm{MDH}}, \\
& \frac{d}{d t}[\mathrm{O}]=V_{\mathrm{MDH}}+V_{\mathrm{PC}}-V_{\mathrm{CS}}-V_{\mathrm{PPCK}}, \\
& \frac{d}{d t}[\mathrm{CO}]=V_{\mathrm{IDH}}+V_{\mathrm{KGDH}}-V_{\mathrm{PC}}+V_{\mathrm{PPCK}}, \\
& \frac{d}{d t}[\mathrm{PEP}]=V_{\mathrm{PPCK}}-V_{\mathrm{GP}}, \\
& \frac{d}{d t}[\mathrm{P}]=V_{\mathrm{IMPORT}}-V_{\mathrm{PC}}-V_{\mathrm{PDH}} .
\end{aligned}
$$

At metabolite steady-state, there is no accumulation of intracellular metabolites and Eqs. (1a-k) give:

$$
\begin{aligned}
& \begin{aligned}
V_{\mathrm{CS}} & =V_{\mathrm{PDH}}=V_{\mathrm{ACON}}=V_{\mathrm{IDH}}=V_{\mathrm{KGDH}}=V_{\mathrm{SUDH}} \\
& =V_{\mathrm{FUM}}=V_{\mathrm{MDH}}
\end{aligned} \\
& \begin{aligned}
V_{\mathrm{PC}} & =V_{\mathrm{PPCK}}
\end{aligned} \\
& \frac{d}{d t}\left[\mathrm{CO}_{2}\right]=2 V_{\mathrm{CS}} \\
& V_{\mathrm{PC}}=V_{\mathrm{GP}} \\
& V_{\mathrm{IMPORT}}=V_{\mathrm{PC}}+V_{\mathrm{CS}}
\end{aligned}
$$

Hence, under metabolite steady-state, the metabolic fluxes of the network of Fig. 3 can be expressed in terms of the citrate synthase and pyruvate carboxylase fluxes only, $V_{\mathrm{CS}}$ and $V_{\mathrm{PC}}$, respectively.

\section{Isotopomer Input-Output Balances}

Similar to the total metabolite concentrations, material balances can be written for each metabolite isotopomer shown in Figs. 3-12. As an example, material balances for the isotopomers generated upon administration of $a \%\left[3-{ }^{13} \mathrm{C}\right]$ pyruvate (Fig. 3) are described below. 


$$
\frac{d}{d t}\left[\mathrm{O}_{T}\right]\left[\begin{array}{l}
\mathrm{O}_{3} \\
\mathrm{O}_{2} \\
\mathrm{O}_{34} \\
\mathrm{O}_{12} \\
\mathrm{O} \\
\mathrm{O}_{4} \\
\mathrm{O}_{1} \\
\mathrm{O}_{13} \\
\mathrm{O}_{24} \\
\mathrm{O}_{23} \\
\mathrm{O}_{123} \\
\mathrm{O}_{234}
\end{array}\right]=V_{\mathrm{MDH}}\left[\begin{array}{l}
\mathrm{M}_{3} \\
\mathrm{M}_{2} \\
\mathrm{M}_{34} \\
\mathrm{M}_{12} \\
\mathrm{M} \\
\mathrm{M}_{4} \\
\mathrm{M}_{1} \\
\mathrm{M}_{13} \\
\mathrm{M}_{24} \\
\mathrm{M}_{23} \\
\mathrm{M}_{123} \\
\mathrm{M}_{234}
\end{array}\right]+V_{\mathrm{PC}}\left[\begin{array}{c}
\mathrm{P}_{3}\left(\frac{1-\mathrm{CO}_{2}^{*}}{2}\right) \\
\mathrm{P}_{3}\left(\frac{1-\mathrm{CO}_{2}^{*}}{2}\right) \\
\mathrm{P}_{3}\left(\frac{\mathrm{CO}_{2}^{*}}{2}\right) \\
\mathrm{P}_{3}\left(\frac{\mathrm{CO}_{2}^{*}}{2}\right) \\
\left(1-\mathrm{P}_{3}\right)\left(1-\mathrm{CO}_{2}^{*}\right) \\
\left(1-\mathrm{P}_{3}\right)\left(\frac{\mathrm{CO}_{2}^{*}}{2}\right) \\
\left(1-\mathrm{P}_{3}\right)\left(\frac{\mathrm{CO}_{2}^{*}}{2}\right) \\
0 \\
0 \\
0 \\
0 \\
0
\end{array}\right]-V_{\mathrm{CS}}\left[\begin{array}{l}
\mathrm{O}_{3} \\
\mathrm{O}_{2} \\
\mathrm{O}_{34} \\
\mathrm{O}_{12} \\
\mathrm{O}_{1} \\
\mathrm{O}_{4} \\
\mathrm{O}_{1} \\
\mathrm{O}_{13} \\
\mathrm{O}_{24} \\
\mathrm{O}_{23} \\
\mathrm{O}_{123} \\
\mathrm{O}_{234}
\end{array}\right]-V_{\mathrm{PPCK}}\left[\begin{array}{l}
\mathrm{O}_{3} \\
\mathrm{O}_{2} \\
\mathrm{O}_{34} \\
\mathrm{O}_{12} \\
\mathrm{O}_{1} \\
\mathrm{O}_{4} \\
\mathrm{O}_{1} \\
\mathrm{O}_{13} \\
\mathrm{O}_{24} \\
\mathrm{O}_{23} \\
\mathrm{O}_{123} \\
\mathrm{O}_{234}
\end{array}\right] .
$$

In Eq. (7) each isotopomer species is represented in relative population, i.e., its concentration is normalized by the total concentration of the same metabolite (for example, $\mathrm{O}_{3}=$ $\left.\left[\mathrm{O}_{3}\right] /\left[\mathrm{O}_{T}\right]\right) . \mathrm{P}_{3}$ is then equal to $a / 100 . V$ is the velocity of the corresponding reaction per subscripts denoted in Fig. 1 in mmol per unit cell mass per unit time, and $* \mathrm{CO}_{2}$ is the fraction of $\mathrm{CO}_{2}$ labeled with ${ }^{13} \mathrm{C}$.

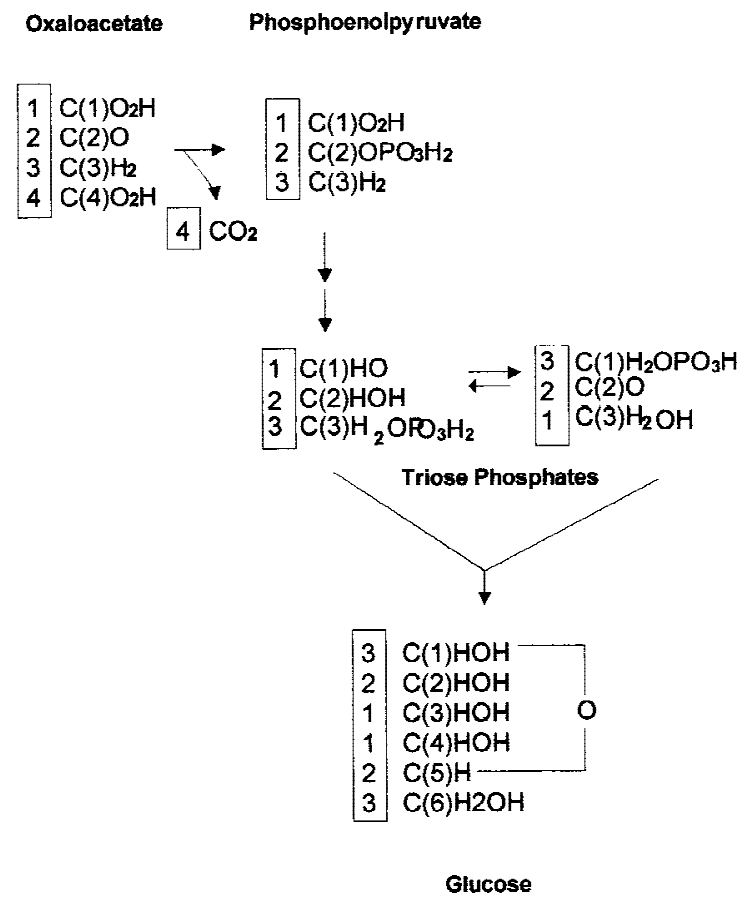

Figure 13. Synthesis of glucose from oxaloacetate via phosphoenolpyruvate. This is the basis for calculating the labeling distribution in glucose via gluconeogenic pathway with oxaloacetate as the primary precursor. The numbers in the parentheses indicate the carbon positions of metabolites, and the numbers in boxes indicate the original carbon position of oxaloacetate.
Similar to OAA, isotopomer balances can be written for citrate/isocitrate (indicated by C), (Eq. (8)), $\alpha$-ketoglutarate (Eq. (9)), succinate (Eq. (10)), malate (Eq. (11)), and the fraction of $\mathrm{CO}_{2}$ labeled with ${ }^{13} \mathrm{C},{ }^{*} \mathrm{CO}_{2}$ (Eq. (12)):

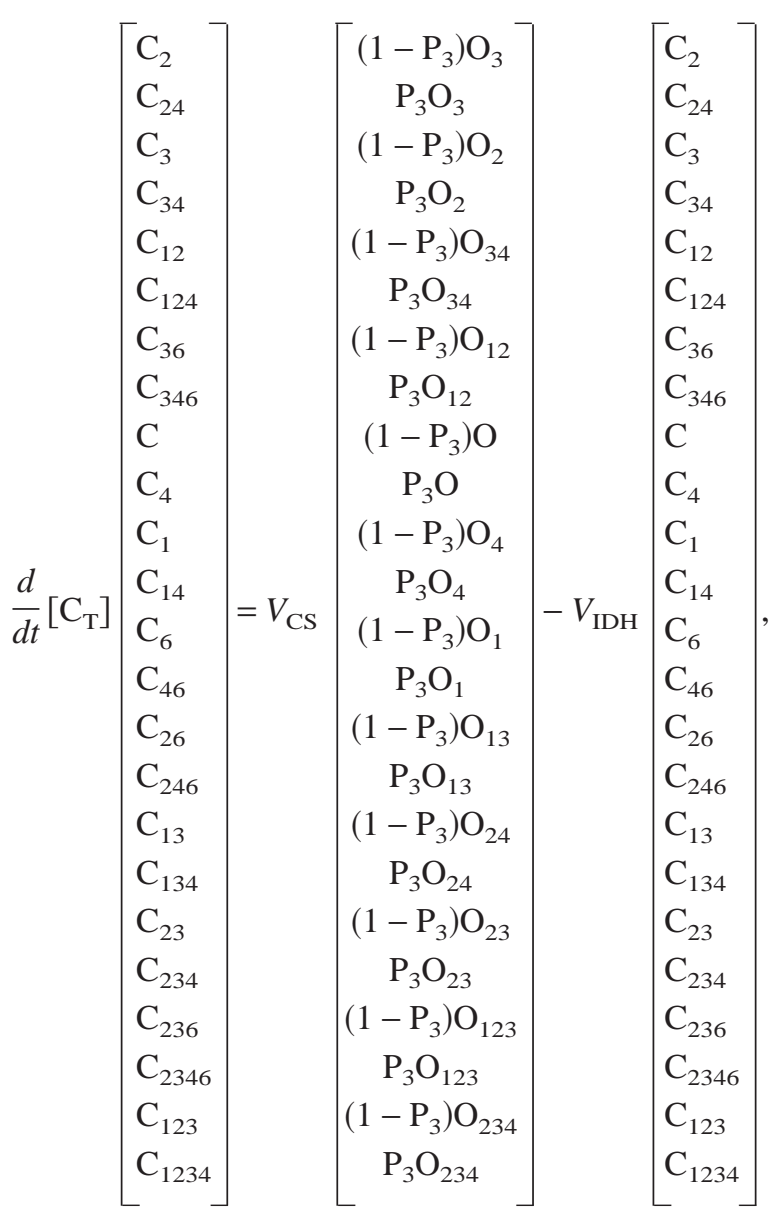




$\frac{d}{d t}\left[\mathrm{~K}_{\mathrm{T}}\left[\begin{array}{l}\mathrm{K}_{2} \\ \mathrm{~K}_{24} \\ \mathrm{~K}_{3} \\ \mathrm{~K}_{34} \\ \mathrm{~K}_{12} \\ \mathrm{~K}_{124} \\ \mathrm{~K} \\ \mathrm{~K}_{4} \\ \mathrm{~K}_{1} \\ \mathrm{~K}_{14} \\ \mathrm{~K}_{13} \\ \mathrm{~K}_{134} \\ \mathrm{~K}_{23} \\ \mathrm{~K}_{234} \\ \mathrm{~K}_{123} \\ \mathrm{~K}_{1234}\end{array}\right]=V_{\mathrm{IDH}}\left[\begin{array}{c}\mathrm{C}_{2}+\mathrm{C}_{26} \\ \mathrm{C}_{24}+\mathrm{C}_{246} \\ \mathrm{C}_{3}+\mathrm{C}_{36} \\ \mathrm{C}_{34}+\mathrm{C}_{346} \\ \mathrm{C}_{12} \\ \mathrm{C}_{124} \\ \mathrm{C}+\mathrm{C}_{6} \\ \mathrm{C}_{4}+\mathrm{C}_{46} \\ \mathrm{C}_{1} \\ \mathrm{C}_{14} \\ \mathrm{C}_{13} \\ \mathrm{C}_{134} \\ \mathrm{C}_{236}+\mathrm{C}_{23} \\ \mathrm{C}_{2346}+\mathrm{C}_{234} \\ \mathrm{C}_{123} \\ \mathrm{C}_{1234}\end{array}\right]-V_{\mathrm{KGDH}}\left[\begin{array}{l}\mathrm{K}_{2} \\ \mathrm{~K}_{24} \\ \mathrm{~K}_{3} \\ \mathrm{~K}_{34} \\ \mathrm{~K}_{12} \\ \mathrm{~K}_{124} \\ \mathrm{~K} \\ \mathrm{~K}_{4} \\ \mathrm{~K}_{1} \\ \mathrm{~K}_{14} \\ \mathrm{~K}_{13} \\ \mathrm{~K}_{134} \\ \mathrm{~K}_{23} \\ \mathrm{~K}_{234} \\ \mathrm{~K}_{123} \\ \mathrm{~K}_{1234}\end{array}\right]\right.$,

(9)

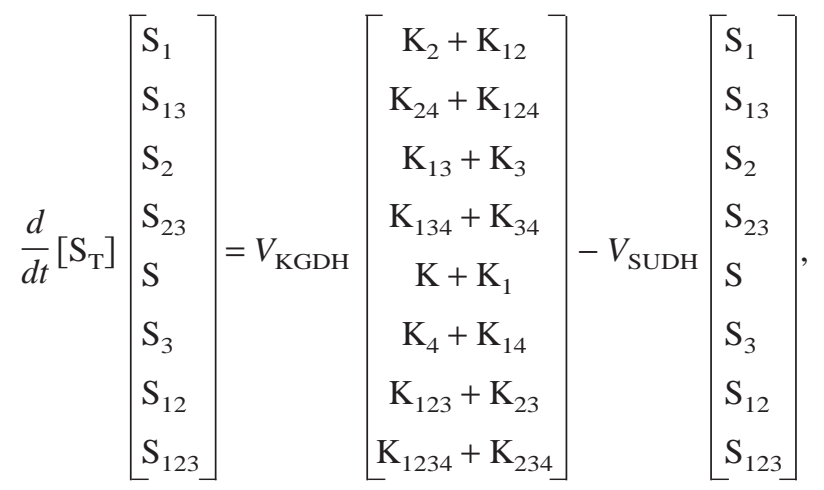

(10)

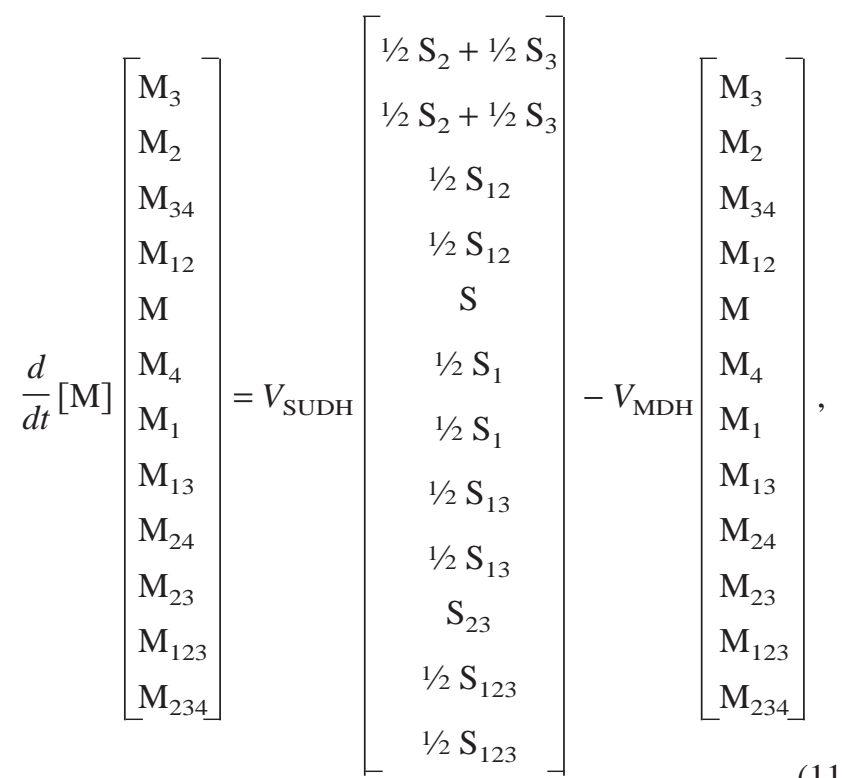

(11)

$$
\begin{aligned}
\frac{d}{d t}\left[\mathrm{CO}_{2 \mathrm{~T}}\right]\left[* \mathrm{CO}_{2}\right]= & V_{\mathrm{IDH}}\left(\mathrm{C}_{36}+\mathrm{C}_{346}+\mathrm{C}_{6}+\mathrm{C}_{46}+\mathrm{C}_{26}\right. \\
& \left.+\mathrm{C}_{246}+\mathrm{C}_{236}+\mathrm{C}_{2346}\right) \\
& +V_{\mathrm{KGDH}}\left(\mathrm{K}_{12}+\mathrm{K}_{124}+\mathrm{K}_{1}+\mathrm{K}_{14}\right. \\
& \left.+\mathrm{K}_{13}+\mathrm{K}_{134}+\mathrm{K}_{123}+\mathrm{K}_{1234}\right) \\
& -V_{\mathrm{PC}}\left(* \mathrm{CO}_{2}\right)+V_{\mathrm{PPCK}}\left(\mathrm{O}_{34}+\mathrm{O}_{4}\right. \\
& \left.+\mathrm{O}_{24}+\mathrm{O}_{234}\right) .
\end{aligned}
$$

At metabolite and isotopic steady-state, using Eqs. (2-6), (10), and (11) give:

$$
\left[\begin{array}{l}
M_{3} \\
M_{2} \\
M_{34} \\
M_{12} \\
M \\
M_{4} \\
M_{1} \\
M_{13} \\
M_{24} \\
M_{23} \\
M_{123} \\
M_{234}
\end{array}\right]=\left[\begin{array}{c}
1 / 2\left(K_{3}+K_{13}+K_{4}+K_{14}\right) \\
1 / 2\left(K_{3}+K_{13}+K_{4}+K_{14}\right) \\
1 / 2\left(K_{23}+K_{123}\right) \\
1 / 2\left(K_{23}+K_{123}\right) \\
K+K_{1} \\
1 / 2\left(K_{2}+K_{12}\right) \\
1 / 2\left(K_{2}+K_{12}\right) \\
1 / 2\left(K_{24}+K_{124}\right) \\
1 / 2\left(K_{24}+K_{124}\right) \\
\left(K_{34}+K_{134}\right) \\
1 / 2\left(K_{234}+K_{1234}\right) \\
1 / 2\left(K_{234}+K_{1234}\right)
\end{array}\right] .
$$

Similarly, from Eqs. (8) and (9):

$$
\left[\begin{array}{l}
\mathrm{K}_{2} \\
\mathrm{~K}_{24} \\
\mathrm{~K}_{3} \\
\mathrm{~K}_{34} \\
\mathrm{~K}_{12} \\
\mathrm{~K}_{124} \\
\mathrm{~K} \\
\mathrm{~K}_{4} \\
\mathrm{~K}_{1} \\
\mathrm{~K}_{14} \\
\mathrm{~K}_{13} \\
\mathrm{~K}_{134} \\
\mathrm{~K}_{23} \\
\mathrm{~K}_{234} \\
\mathrm{~K}_{123} \\
\mathrm{~K}_{1234}
\end{array}\right]=\left[\begin{array}{c}
\left(1-\mathrm{P}_{3}\right)\left(\mathrm{O}_{3}+\mathrm{O}_{13}\right) \\
\mathrm{P}_{3}\left(\mathrm{O}_{3}+\mathrm{O}_{13}\right) \\
\left(1-\mathrm{P}_{3}\right)\left(\mathrm{O}_{2}+\mathrm{O}_{12}\right) \\
\mathrm{P}_{2}\left(\mathrm{O}_{2}+\mathrm{O}_{12}\right) \\
\left(1-\mathrm{P}_{3}\right) \mathrm{O}_{34} \\
\mathrm{P}_{3} \mathrm{O}_{34} \\
\left(1-\mathrm{P}_{3}\right)\left(\mathrm{O}+\mathrm{O}_{1}\right) \\
\mathrm{P}_{3}\left(\mathrm{O}+\mathrm{O}_{1}\right) \\
\left(1-\mathrm{P}_{3}\right) \mathrm{O}_{4} \\
\mathrm{P}_{3} \mathrm{O}_{4} \\
\left(1-\mathrm{P}_{3}\right) \mathrm{O}_{24} \\
\mathrm{P}_{3} \mathrm{O}_{24} \\
\left(1-\mathrm{P}_{3}\right)\left(\mathrm{O}_{23}+\mathrm{O}_{123}\right) \\
\mathrm{P}_{3}\left(\mathrm{O}_{23}+\mathrm{O}_{123}\right) \\
\left(1-\mathrm{P}_{3}\right) \mathrm{O}_{234} \\
\mathrm{P}_{3} \mathrm{O}_{234}
\end{array}\right]
$$

When Eqs. (13) and (14) are combined and the result is inserted into Eq. (7), the isotopomer balance of OAA at metabolite and isotopic stead-state becomes: 


$$
V_{\mathrm{cs}}\left[\begin{array}{c}
1 / 2\left[\left(1-\mathrm{P}_{3}\right)\left(\mathrm{O}_{2}+\mathrm{O}_{12}\right)+\left(1-\mathrm{P}_{3}\right) \mathrm{O}_{24}+\mathrm{P}_{3}\left(\mathrm{O}+\mathrm{O}_{1}\right)+\mathrm{P}_{3} \mathrm{O}_{4}\right] \\
1 / 2\left[\left(1-\mathrm{P}_{3}\right)\left(\mathrm{O}_{2}+\mathrm{O}_{12}\right)+\left(1-\mathrm{P}_{3}\right) \mathrm{O}_{24}+\mathrm{P}_{3}\left(\mathrm{O}+\mathrm{O}_{1}\right)+\mathrm{P}_{3} \mathrm{O}_{4}\right] \\
1 / 2\left[\left(1-\mathrm{P}_{3}\right)\left(\mathrm{O}_{23}+\mathrm{O}_{123}\right)+\left(1-\mathrm{P}_{3}\right) \mathrm{O}_{234}\right] \\
1 / 2\left[\left(1-\mathrm{P}_{3}\right)\left(\mathrm{O}_{23}+\mathrm{O}_{123}\right)+\left(1-\mathrm{P}_{3}\right) \mathrm{O}_{234}\right] \\
\left(1-\mathrm{P}_{3}\right)\left(\mathrm{O}+\mathrm{O}_{1}\right)+\left(1-\mathrm{P}_{3}\right) \mathrm{O}_{4} \\
1 / 2\left[\left(1-\mathrm{P}_{3}\right)\left(\mathrm{O}_{3}+\mathrm{O}_{13}\right)+\left(1-\mathrm{P}_{3}\right) \mathrm{O}_{34}\right] \\
1 / 2\left[\mathrm{P}_{3}\left(\mathrm{O}_{3}+\mathrm{O}_{13}\right)+\mathrm{P}_{3} \mathrm{O}_{34}\right] \\
1 / 2\left[\mathrm{P}_{3}\left(\mathrm{O}_{3}+\mathrm{O}_{13}\right)+\mathrm{P}_{3} \mathrm{O}_{34}\right] \\
\mathrm{P}_{3}\left(\mathrm{O}_{2}+\mathrm{O}_{12}\right)+\mathrm{P}_{3} \mathrm{O}_{24} \\
1 / 2\left[\mathrm{P}_{3}\left(\mathrm{O}_{23}+\mathrm{O}_{123}\right)+\mathrm{P}_{3} \mathrm{O}_{234}\right] \\
1 / 2\left[\mathrm{P}_{3}\left(\mathrm{O}_{23}+\mathrm{O}_{123}\right)+\mathrm{P}_{3} \mathrm{O}_{234}\right]
\end{array}\right]+V_{\mathrm{PC}}\left[\begin{array}{c}
\mathrm{P}_{3}\left(\frac{1-\mathrm{CO}_{2}^{*}}{2}\right) \\
\mathrm{P}_{3}\left(\frac{\mathrm{CO}_{2}^{*}}{2}\right) \\
\mathrm{P}_{3}\left(\frac{\mathrm{CO}_{2}^{*}}{2}\right) \\
\left(1-\mathrm{P}_{3}\right)\left(1-\mathrm{CO}_{2}^{*}\right) \\
\left(1-\mathrm{P}_{3}\right)\left(\frac{\mathrm{CO}_{2}^{*}}{2}\right) \\
\left(1-\mathrm{P}_{3}\right)\left(\frac{\mathrm{CO}_{2}^{*}}{2}\right) \\
0 \\
0 \\
0 \\
0 \\
0
\end{array}\right]=\left(V_{\mathrm{CS}}+V_{\left.\mathrm{PC}_{3}\right)}\left[\begin{array}{l}
\mathrm{O}_{3} \\
\mathrm{O}_{2} \\
\mathrm{O}_{34} \\
\mathrm{O}_{12} \\
\mathrm{O} \\
\mathrm{O}_{4} \\
\mathrm{O}_{1} \\
\mathrm{O}_{13} \\
\mathrm{O}_{24} \\
\mathrm{O}_{23} \\
\mathrm{O}_{123} \\
\mathrm{O}_{234}
\end{array}\right],\right.
$$

where, after combining Eqs. (8), (9), and (12),

$$
* \mathrm{CO}_{2}=\mathrm{O}_{34}+\mathrm{O}_{4}+\mathrm{O}_{24}+\mathrm{O}_{234}
$$

From the above equations (Eqs. (13-16)), it can be seen that, under metabolite and isotopic steady state, the relative populations of all isotopomers, and, through them, the degree of label enrichment, of intermediate metabolites can be determined as a function of the citrate synthase, $V_{\mathrm{CS}}$, and pyruvate carboxylase, $V_{\mathrm{PC}}$, fluxes only. Therefore, comparison of the theoretical expressions with experimental data from ${ }^{13} \mathrm{C}$ NMR spectra and from isotopic molecular weight distribution measurements by GC-MS, combined with the extracellular accumulation rates measurements, will allow the determination of the intracellular fluxes $V_{\mathrm{CS}}$ and $V_{\mathrm{PC}}$. This is the basis for intracellular flux determination from measurements on intermediary metabolites.

For the cases depicted in Figs. 3-12, if $x$ is defined as the probability that OAA exists the TCA cycle via the PEP carboxykinase (PPCK) reaction, $(1-x)$ will denote the probability that OAA will reenter the TCA cycle via citrate synthase (CS). In terms of $x$ one can write:

$$
\frac{x}{1-x}=\frac{V_{\mathrm{PPCK}}}{V_{\mathrm{CS}}}=\frac{V_{\mathrm{PC}}}{V_{\mathrm{CS}}}
$$

Likewise, we let $y$ be the probability of bicarbonate fixed into pyruvate to be labeled with ${ }^{13} \mathrm{C},{ }^{*} \mathrm{CO}_{2}$. If there is no pathway that generates and consumes $\mathrm{CO}_{2}$ other than the reactions considered in this model, $y$ can be expressed in terms of $x$ only.
In the case of acetate utilization, we introduce yet another variable $z$ to denote the probability of isocitrate to be utilized via the GS pathway. Then $(1-z)$ is the fraction utilized via the TCA cycle. Therefore, the ratio of flux via the GS pathway to flux via the TCA cycle can be expressed as

$$
\frac{z}{1-z}=\frac{V_{\mathrm{GS}}}{V_{\mathrm{TCA}}}
$$

For the case of Fig. 3, for a given label enrichment of pyruvate at carbon 3 , we can obtain the relative populations of all OAA isotopomers as a function of $x$ and $y . y$ can be expressed exclusively in terms of $x$ as well (see Eq. (16)). Accordingly, Eq. (14) gives the relative population of all $\alpha \mathrm{KG}$ isotopomers as a function of $x$ and $y$. For the case of $100 \%$ enriched pyruvate $\left(\mathrm{P}_{3}=1\right)$, the results of OAA, as well as the glucose and glutamate ${ }^{13} \mathrm{C}$ enrichment patterns, are shown in the first column of Table I. Columns 2 and 3 of Table I summarize equivalent results, when $100 \%$ $\left[2-{ }^{13} \mathrm{C}\right]-$ and $\left[1-{ }^{13} \mathrm{C}\right]$ pyruvate are used, respectively. Tables II and III summarize similar results obtained with labeled acetate for the cases of the three models of Fig. 2. In all the cases, acetate is assumed to be $100 \%$ enriched at the designated position. It should be noted that $\mathrm{G}$ and $\mathrm{K}$ are used interchangeably since the isotopomer distributions of glutamate and $\alpha$-ketoglutarate are identical.

The assumptions invoked in the derivation of the expressions of Tables I-III are:

- There is no label recycling due to operation of futile cycles such as the "pyruvate $\rightarrow$ OAA $\rightarrow$ PEP $\rightarrow$ pyruvate" and "malate $\rightarrow$ pyruvate $\rightarrow$ OAA $\rightarrow$ malate" cycles. 
Table I. Steady-state distribution of oxaloacetate $(\mathrm{O})$ and glutamate $(\mathrm{G})$ isotopemers and relative carbon enrichments in glucose and glutamate following the utilization of $100 \%\left[3-{ }^{13} \mathrm{C}\right]$ pyruvate (label diagram in Fig. 4), $100 \%\left[2-{ }^{13} \mathrm{C}\right]$ pyruvate (Fig. 5) and $100 \%\left[1-{ }^{13} \mathrm{C}\right]$ pyruvate (Fig. 6) through the major pathways described in Fig. 1. $y$ can be obtained exclusively as a function of $x$ (see text): $y=(1-x) /\left(2+x-x^{2}\right)$ in $100 \%\left[3-{ }^{13} \mathrm{C}\right]$ pyruvate; $y=\left(1+x-2 x^{2}\right) /\left(2+x-x^{2}\right)$ in $100 \%\left[2-{ }^{13} \mathrm{C}\right]$ pyruvate; $y=x /(2-x)$ in $100 \%\left[1-{ }^{13} \mathrm{C}\right]$ pyruvate. Glutamate $(\mathrm{G})$ and $\alpha$-ketoglutarate $(\mathrm{K})$ are used interchangeably since the labeling patterns of the two are identical. Glucose synthesized via the gluconeogenic pathway with these substrates has the following enrichment pattern: C-1 = C-6; C-2 = C-5; C-3 = C-4.

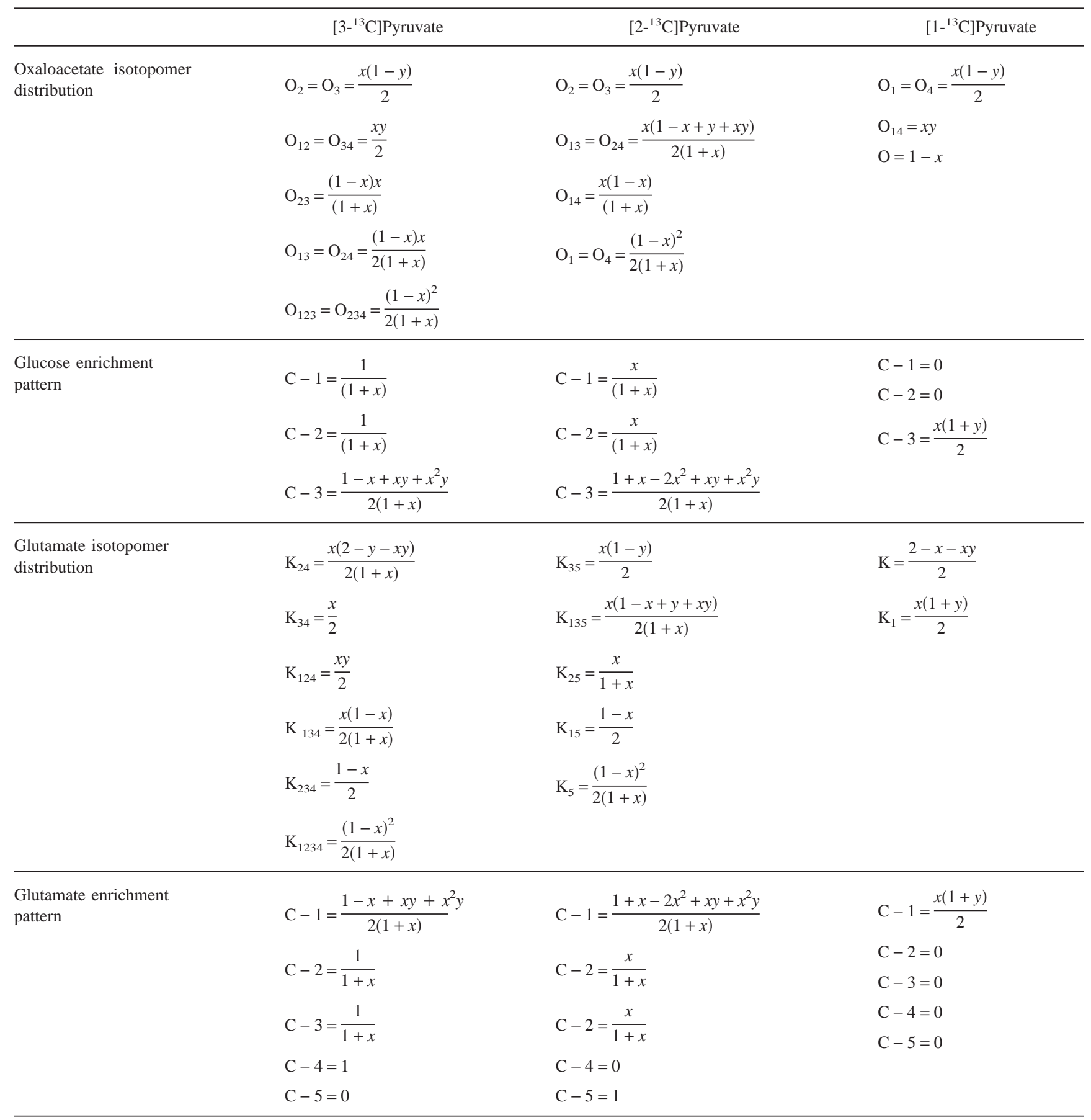

- There is no compartmentalization of metabolites and homogenous pools exist which are common to the TCA cycle and other pathways.

- There is no net flux to biosynthesis except in the formation of glucose.

- There is no label scrambling by the operation of the PPP which could redistribute the label of glucose synthesized via the gluconeogenic pathway.

- Metabolic and isotopic steady states are reached.

- Isotopic dilution due to presence of unlabeled endogenous pools is negligible.

The model can be expanded to include any of the above 
Table II. Steady-state distribution of oxaloacetate and glutamate isotopomers and relative carbon enrichments in glucose and glutamate following $100 \%$ $\left[2-{ }^{13} \mathrm{C}\right]$ acetate administration through the three different model pathways described in Fig. 2. In Model II and III, $y$ can be obtained exclusively as a function of $x: y=(1-x)^{2} /\left(2+x-x^{2}\right)$ and $y=\left(1+x^{2}\right) /\left(2+x-x^{2}\right)$ respectively.

\begin{tabular}{|c|c|c|c|}
\hline & \multicolumn{3}{|c|}{$\left[2-{ }^{13} \mathrm{C}\right]$ Acetate } \\
\hline & Via Model I & Via Model II & Via Model III \\
\hline $\begin{array}{l}\text { Oxaloacetate isotopomer } \\
\text { distribution }\end{array}$ & $\begin{array}{l}\mathrm{O}_{23}=z \\
\mathrm{O}_{123}=\mathrm{O}_{234}=\frac{1-z}{2}\end{array}$ & $\begin{array}{l}\mathrm{O}=x-x y \\
\mathrm{O}_{1}=\mathrm{O}_{4}=\frac{x y}{2} \\
\mathrm{O}_{2}=\mathrm{O}_{3}=\frac{x(1-x)}{2} \\
\mathrm{O}_{23}=\frac{(1-x)^{2} x}{(1+x)} \\
\mathrm{O}_{13}=\mathrm{O}_{24}=\frac{(1-x)^{2} x}{2(1+x)} \\
\mathrm{O}_{123}=\mathrm{O}_{234}=\frac{(1-x)^{3}}{2(1+x)}\end{array}$ & $\begin{array}{l}\mathrm{O}_{13}=\mathrm{O}_{24}=\frac{x(2-y-x y)}{2(1+x)} \\
\mathrm{O}_{134}=\mathrm{O}_{124}=\frac{x y}{2} \\
\mathrm{O}_{23}=\frac{x(1-x)}{(1+x)} \\
\mathrm{O}_{123}=\mathrm{O}_{234}=\frac{(1-x)^{2}}{2(1+x)}\end{array}$ \\
\hline Glucose enrichment pattern & $\begin{array}{l}C-1=1 \\
C-2=1 \\
C-1=\frac{1-z}{2}\end{array}$ & $\begin{array}{l}C-1=\frac{1-x}{(1+x)} \\
C-2=\frac{1-x}{(1+x)} \\
C-3=\frac{1-2 x+x^{2}+x y+x^{2} y}{2(1+x)}\end{array}$ & $\begin{array}{l}\mathrm{C}-1=\frac{1}{(1+x)} \\
\mathrm{C}-2=\frac{1}{(1+x)} \\
\mathrm{C}-3=\frac{1+x^{2}+x y+x^{2} y}{2(1+x)}\end{array}$ \\
\hline $\begin{array}{l}\text { Glutamate isotopomer } \\
\text { distribution }\end{array}$ & $\begin{array}{l}\mathrm{K}_{234}=\frac{1+z}{2} \\
\mathrm{~K}_{1234}=\frac{1-z}{2}\end{array}$ & $\begin{array}{l}\mathrm{K}_{4}=x-\frac{x y}{2} \\
\mathrm{~K}_{14}=\frac{x y}{2} \\
\mathrm{~K}_{24}=\frac{x(1-x)}{(1+x)} \\
\mathrm{K}_{34}=\frac{(1-x) x}{2} \\
\mathrm{~K}_{134}=\frac{x(1-x)^{2}}{2(1+x)} \\
\mathrm{K}_{234}=\frac{(1-x)^{2}}{2} \\
\mathrm{~K}_{1234}=\frac{(1-x)^{3}}{2(1+x)}\end{array}$ & $\begin{array}{l}\mathrm{K}_{24}=\frac{x(2-y-x y)}{2(1+x)} \\
\mathrm{K}_{134}=\frac{x}{(1+x)} \\
\mathrm{K}_{124}=\frac{x y}{2} \\
\mathrm{~K}_{234}=\frac{1-x}{2} \\
\mathrm{~K}_{1234}=\frac{(1-x)^{2}}{2(1+x)}\end{array}$ \\
\hline Glutamate enrichment pattern & $\begin{array}{l}\mathrm{C}-1=\frac{1-z}{2} \\
\mathrm{C}-2=1 \\
\mathrm{C}-3=1 \\
\mathrm{C}-4=1 \\
\mathrm{C}-5=0\end{array}$ & $\begin{array}{l}\mathrm{C}-1=\frac{1-2 x+x^{2}+x y+x^{2} y}{2(1+x)} \\
\mathrm{C}-2=\frac{1-x}{1+x} \\
\mathrm{C}-3=\frac{1-x}{1+x} \\
\mathrm{C}-4=1 \\
\mathrm{C}-5=0\end{array}$ & $\begin{array}{l}\mathrm{C}-1=\frac{x y+x^{2} y+1+x^{2}}{2(1+x)} \\
\mathrm{C}-2=\frac{1}{1+x} \\
\mathrm{C}-3=\frac{1}{1+x} \\
\mathrm{C}-4=1 \\
\mathrm{C}-5=0\end{array}$ \\
\hline
\end{tabular}


Table III. Steady-state distribution of oxaloacetate and glutamate isotopomers and relative carbon enrichments in glucose and glutamate following $100 \%$ $\left[1-{ }^{13} \mathrm{C}\right]$ acetate administration through the three different model pathways described in Fig. 2.

\begin{tabular}{|c|c|c|c|}
\hline & & {$\left[1-{ }^{13} \mathrm{C}\right]$ Acetate } & \\
\hline & Via Model I & Via Model II & Via Model III \\
\hline $\begin{array}{l}\text { Oxaloacetate isotopomer } \\
\text { distribution }\end{array}$ & $\begin{array}{l}\mathrm{O}_{14}=z \\
\mathrm{O}_{1}=\mathrm{O}_{4}=\frac{1-z}{2}\end{array}$ & $\begin{array}{l}\mathrm{O}=x-x y \\
\mathrm{O}_{1}=\mathrm{O}_{4}=\frac{1-x+x y}{2}\end{array}$ & $\begin{array}{l}\mathrm{O}_{2}=\mathrm{O}_{3}=\frac{x(1-y)}{2} \\
\mathrm{O}_{13}=\mathrm{O}_{24}=\frac{x(1-x+y+x y)}{2(1+x)} \\
\mathrm{O}_{14}=\frac{x(1-x)}{(1+x)} \\
\mathrm{O}_{1}=\mathrm{O}_{4}=\frac{(1-x)^{2}}{2(1+x)}\end{array}$ \\
\hline Glucose enrichment pattern & $\begin{array}{l}C-1=0 \\
C-2=0 \\
C-3=\frac{1+z}{2}\end{array}$ & $\begin{array}{l}\mathrm{C}-1=0 \\
\mathrm{C}-2=0 \\
\mathrm{C}-3=\frac{1-x+x y}{2}\end{array}$ & $\begin{array}{l}\mathrm{C}-1=\frac{x}{(1+x)} \\
\mathrm{C}-2=\frac{x}{(1+x)} \\
\mathrm{C}-3=\frac{1+x-2 x^{2}+x y+x^{2} y}{2(1+x)}\end{array}$ \\
\hline $\begin{array}{l}\text { Glutamate isotopomer } \\
\text { distribution }\end{array}$ & $\begin{array}{l}\mathrm{K}_{15}=\frac{1-z}{2} \\
\mathrm{~K}_{5}=\frac{1+z}{2}\end{array}$ & $\begin{array}{l}\mathrm{K}_{15}=\frac{1-x+x y}{2} \\
\mathrm{~K}_{5}=\frac{1+x-x y}{2}\end{array}$ & $\begin{array}{l}\mathrm{K}_{35}=\frac{x(1-y)}{2} \\
\mathrm{~K}_{135}=\frac{x(1-x+y+x y)}{2(1+x)} \\
\mathrm{K}_{25}=\frac{x}{1+x} \\
\mathrm{~K}_{15}=\frac{1-x}{2} \\
\mathrm{~K}_{5}=\frac{(1-x)^{2}}{2(1+x)}\end{array}$ \\
\hline Glutamate enrichment pattern & $\begin{array}{l}\mathrm{C}-1=\frac{1-z}{2} \\
\mathrm{C}-2=0 \\
\mathrm{C}-3=0 \\
\mathrm{C}-4=0 \\
\mathrm{C}-5=1\end{array}$ & $\begin{array}{l}\mathrm{C}-1=\frac{1-x+x y}{2} \\
\mathrm{C}-2=0 \\
\mathrm{C}-3=0 \\
\mathrm{C}-4=0 \\
\mathrm{C}-5=1\end{array}$ & $\begin{array}{l}\mathrm{C}-1=\frac{1+x-2 x^{2}+x y+x^{2} y}{2(1+x)} \\
\mathrm{C}-2=\frac{x}{1+x} \\
\mathrm{C}-3=\frac{x}{1+x} \\
\mathrm{C}-4=0 \\
\mathrm{C}-5=1\end{array}$ \\
\hline
\end{tabular}

$y=(1-x) /(2-\mathrm{x})$ in Model II and $y=\left(1+x-2 x^{2}\right) /\left(2+x-x^{2}\right)$ in Model III.

pathways not considered in the presented structures or any kind of compartmentalization. Their introduction increases, however, the label scrambling in the network. It should be difficult then to derive an analytical solution, and for those cases a numerical model is required (see Discussion).

\section{DISCUSSION}

Most metabolic NMR experiments are limited to the measurement of ${ }^{13} \mathrm{C}$ label enrichment at specific carbon atoms of various metabolites. Results as those reported in Tables
I-III not only allow the correct interpretation of such label enrichment data but also extend the amount of information that can be derived from NMR experiments through the analysis of the fine structure of NMR spectra as well as the determination of the molecular weight distribution of metabolic isotopomers.

With respect to the interpretation of ${ }^{13} \mathrm{C}$ enrichment data, the degree of enrichment at various carbon atoms can be obtained as the sum of the corresponding isotopomers using expressions as those reported in Tables I-III. Referring, for example, to the use of $100 \%\left[3-{ }^{13} \mathrm{C}\right]$ pyruvate, the relative 
degree of enrichment at each carbon position of $\alpha$-ketoglutarate can be calculated as the sum of all isotopomer species that contain the labeled carbon at that particular position. This is reflected in the following equations:

$$
\begin{aligned}
& \mathrm{C}-1=\mathrm{K}_{124}+\mathrm{K}_{134}+\mathrm{K}_{1234} \\
& \mathrm{C}-2=\mathrm{K}_{24}+\mathrm{K}_{124}+\mathrm{K}_{234}+\mathrm{K}_{1234} \\
& \mathrm{C}-3=\mathrm{K}_{34}+\mathrm{K}_{134}+\mathrm{K}_{234}+\mathrm{K}_{1234} \\
& \mathrm{C}-4=\mathrm{K}_{24}+\mathrm{K}_{34}+\mathrm{K}_{124}+\mathrm{K}_{134}+\mathrm{K}_{234}+\mathrm{K}_{1234}=1 \\
& \mathrm{C}-5=0
\end{aligned}
$$

From the isotopomer distributions, the fine structure of NMR peaks at specific carbon atom locations can be further analyzed. Referring again to the results of Table I for the case of $100 \%$ [3- $\left.{ }^{13} \mathrm{C}\right]$ pyruvate it can be seen that the glutamate $\mathrm{C}-2$ resonance will be split into nine-lines centered at $55.5 \mathrm{ppm}$. The nine-lines splitting at C-2 will be the sum of a singlet due to $\mathrm{G}_{24}$, a doublet with coupling constant $J_{12}$ due to $\mathrm{G}_{124}$, a doublet with coupling constant $J_{23}$ due to $\mathrm{G}_{234}$, and a quartet due to $\mathrm{G}_{1234}$. Two different doublets occur as a result of the difference between the coupling constants $J_{12}(53.5 \mathrm{~Hz})$ and $J_{23}(34.6 \mathrm{~Hz})$. On the other hand, the line splitting at C-3 due to $\mathrm{G}_{1234}$ is a triplet with an intensity ratio 1:2:1 due to the similar values of $J_{23}$ and $J_{34}$. Thus, the relative amounts of the isotopomers will define the exact nature of the fine structure of the NMR spectra. Since the relative amounts of isotopomers depend on metabolic flux distributions (as represented by the parameters $x$ and $z$ (Eqs. (17 and 18))), it is clear that the NMR spectra fine structure contains useful information about the overall distribution of metabolic fluxes.

The same isotopomer distributions can further be applied to the determination of molecular weight distributions of different isotopomers. For examples, for the case of Fig. 4, the relative amount of glutamate molecules with normal molecular weight $M$ (corresponding to the absence of ${ }^{13} \mathrm{C}$ label from all carbon atoms) is equal to 0 as well as the relative amount of isotopomers with molecular weight $(M+$ 1) (corresponding to one labeled carbon atom). However, the relative amount of isotopomers with molecular weight $(M+2)$ will be equal to the sum of $\mathrm{K}_{24}$ and $\mathrm{K}_{34}$, the relative amount of isotopomers with molecular weight $(M+3)$ will be equal to the sum of $\mathrm{K}_{124}, \mathrm{~K}_{134}$, and $\mathrm{K}_{234}$, and, finally, the relative amount of isotopomers with molecular weight $(M+$ 4) will be equal to $K_{1234}$. Such molecular weight distributions can be obtained by GC-MS and can provide further information about the origin of the isotopomers and the corresponding metabolic fluxes.

It is noted that a great deal of redundancy is built into the calculations. For example, isotopomer distributions, molecular weight distributions, and fine structure of NMR spectra depend on the two parameters $x$ and $z$ in the cases considered in Tables I-III. Any two of these measurements could be used for the determination of the unknown parameters $x$ and $z$, and the rest of the data could then be employed to test the consistency of the obtained values of $x$ and $z$. In practice, a better approach may be to fit all measurements to the values of the two unknown parameters $x, z$ and use the residual mean square as a measure of the accuracy of the fit. Low values of the residual mean square will indicate a good fit, while large values will be an indication of the presence of errors either in the measurements or in the assumed biochemical pathways. In the event that inconsistencies are identified, one can try eliminating various measurements one at a time and test the accuracy of the fit obtained with the remaining measurements. If a significant improvement is obtained upon eliminating one measurement, this would make the eliminated measurement suspect of containing gross errors suggesting that it should not be considered in the fit. If none of the measurements are so identified as containing gross errors, then the process can be repeated by altering the biochemical pathways included in the derivation of the corresponding equations, until a satisfactory fit is obtained.

The methodology presented in this paper maintains a focus on the determination of metabolic fluxes instead of concentrations of metabolites. We believe that intracellular fluxes can be very informative about factors controlling the flux of carbon and energy in metabolic networks. Furthermore, the results rely on measurements of secreted metabolites or intracellular metabolites in cell lysates. There is no need for in situ NMR measurements and the elaborate arrangements required for this purpose.

The results presented allow one to optimize the selection of the type of labeled substrates. It is clear from Table I that different enrichments and molecular weight distributions are obtained from the use of $\left[3-{ }^{13} \mathrm{C}\right]$ pyruvate, $\left[2-{ }^{13} \mathrm{C}\right]$ pyruvate, or $\left[1-{ }^{13} \mathrm{C}\right]$ pyruvate as carbon substrate. The enrichments and the molecular weight distributions depend also on the label enrichment of the substrate (see Eq. (15)). Although metabolic pathways should remain unaltered with the use of different labeled substrates, differences in the structure of NMR spectra obtained with different labeled substrates can be extremely elucidating of metabolic fluxes contributing to the utilization of the pyruvate metabolite. Judicious choice of the specific labeled substrate can thus be instrumental in the type of results that will be obtained by ${ }^{13} \mathrm{C}$ NMR experiments.

Clearly, a great deal of information can be extracted from conventional NMR data in light of the analysis presented. The availability of expressions as those presented in Tables I-III facilitates greatly the analysis of such measurements. However, analytical solutions for isotopomer distributions cannot be expected in general to be available or easily extractable for any configuration of biochemical pathways analyzed. It is possible that certain network structures will not be amenable to exact analytical solution of the type reported. In such cases, the isotopomer distributions will have to be obtained numerically, although they still contain the same amount and type of information. Suitable computer programs that facilitate the analysis of label transfer and calculation of isotopomer distribution (e.g., Schmidt et al., 1997) will be invaluable in maximizing the information obtainable from these experiments and providing the best experimental design. 


\section{NOMENCLATURE}

$a(\%) \quad$ percent enrichment of the substrate at the specified carbon atom

Ac acetyl-CoA

C citrate

CS citrate synthase

F fumarate

G glutamate

GS glyoxylate shunt

Gx glyoxylate

K $\quad \alpha$-ketoglutarate

M malate

O, OAA oxaloacetate

$\mathrm{P} \quad$ pyruvate

PC pyruvate carboxylase

PEP phosphoenolpyruvate

PPCK phosphoenolpyruvate carboxykinase

$\mathrm{S} \quad$ succinate

TA transaminase

TCA tricarboxylic acid cycle

$V_{i} \quad$ flux through enzyme $i$

$x \quad$ probability of oxaloacetate to exit the TCA cycle

$(1-x) \quad$ probability of oxaloacetate to enter the TCA cycle

$y \quad$ probability of bicarbonate labeled with ${ }^{13} \mathrm{C}$

$(1-y) \quad$ probability of unlabeled bicarbonate

$z \quad$ probability of isocitrate to be utilized via the GS pathway

$(1-z)$ probability of isocitrate to be utilized via the TCA cycle

Support by the National Science Foundation (Grant No. BCS9311509) and the Department of Energy BES (Grant No. DEFG02-94ER14487) is gratefully acknowledged.

\section{References}

Annison EF, Leng RA, Lindsay DB, White RR. 1963. The metabolism of acetic acid, propionic acid and butyric acid in sheep. Biochem $\mathrm{J}$ 88:248-252.

Chance EM, Seeholzer SH, Kobayashi K, Williamson JR. 1983. Mathematical analysis of isotope labeling in the citric acid cycle with applications to ${ }^{13} \mathrm{C}$ NMR studies in perfused rat hearts. J Biol Chem 258:13785-13794.

Crawford A, Hunter BK, Wood JM. 1987. Nuclear magnetic resonance spectroscopy reveals the metabolic origins of proline excreted by an Escherichia coli derivative during growth on $\left[{ }^{13} \mathrm{C}\right]$ acetate. Appl Environ Microbiol 53:2445-2451.

Desmoulin F, Canioni P, Cozzone PJ. 1985. Glutamate-glutamine metabolism in the perfused rat liver: ${ }^{13} \mathrm{C}$-NMR study using $\left(2-{ }^{13} \mathrm{C}\right)$-enriched acetate. FEBS Lett 185:29-32.

Dickinson JR, Dawes IW, Boyd ASF, Baxter RL. 1983. ${ }^{13} \mathrm{C}$ NMR studies of acetate metabolism during sporulation of Saccheromyces cerevisiae. Proc Natl Acad Sci USA 80:5847-5851.

Di Donato L, Des Rosiers C, Montgomery JA, David F, Garneau M, Brunengraber H. 1993. Rates of gluconeogenesis and citric acid cycle in perfused livers, assessed from the mass spectrometric assay of the ${ }^{13} \mathrm{C}$ labelling patterns of glutamate. J Biol Chem 268:4170-4180.

Exton JH, Park CR. 1967. Control of gluconeogenesis in liver: I. General features of gluconeogenesis in the perfused livers of rats. J Biol Chem 242:2622-2636.

Gopher A, Vaisman N, Mandel H, Lapidot A. 1990. Determination of fructose metabolic pathways in normal and fructose-intolerant children-A ${ }^{13} \mathrm{C}$ NMR study using $\left[\mathrm{U}-{ }^{13} \mathrm{C}\right]$ fructose. Proc Natl Acad Sci USA 87:5449-5453.

Graham DY, Klein PD, Opekun AR, Boutton TW. 1988. Effect of age on the frequency of active Campylobacter pylori infection diagnosed by the $\left[{ }^{13} \mathrm{C}\right]$ urea breath test in normal subjects and patients with peptic ulcer disease. J Infect Dis 157:777-780.
Hofmann AF, Lauterburg BH. 1977. Breath test with isotopes of carbon: Progress and potential. J Lab Clin Med 90:405-411.

den Hollander JA, Ugurbil K, Brown TR, Bednar M, Redfield C, Shulman RG. 1986. Studies of anaerobic and aerobic glycolysis in Saccharomyces cerevisiae. Biochemistry 25:203-211.

Kalderon B, Korman SH, Gutman A, Lapidot A. 1989a. Glucose recycling and production in glycogenosis type-I and type-III: Stable isotope technique study. Am J Physiol 257:E346-E353.

Kalderon B, Korman SH, Gutman A, Lapidot A. 1989b. Estimation of glucose carbon recycling in children with glycogen storage disease: A ${ }^{13} \mathrm{C}$ NMR study using $\left[\mathrm{U}-{ }^{13} \mathrm{C}\right]$ glucose. Proc Natl Acad Sci USA 86:4690-4694.

Kassel DB, Glerum M, Robinson BH, Sweeley CC. (1989). Determination of $\left[\mathrm{U}_{-}{ }^{13} \mathrm{C}\right]$ glucose turnover into various metabolite pools for the differential diagnosis of lactic acidemias. Anal Biochem 176:382-389.

Katz J, Grunnet N. 1979. Estimation of metabolic pathways in steady state in vitro. Rates of tricarboxylic acid and pentose cycles. In: Kornberg HL, editor. Techniques in Metabolic Research. New York: Elsevier/ North-Holland Scientific Publishers Ltd. p 1-18.

Kurumaya K, Kajiwara M, Abel T, Hirano S, Kokubun N. 1988. Synthesis of $\left[{ }^{13} \mathrm{C}\right]$ phenacetin and its application to the breath test for the diagnosis of liver disease. Chem Pharm Bull 36:2679-2681.

Lacroix M, Mosora F, Pontus M, Lefebvre P, Luyckx A, Lopez-Habib G. 1973. Glucose naturally labeled with carbon-13: Use for metabolic studies in man. Science 181:445-446.

Magnusson I, Schumann WC, Bartsch GE, Chandramouli V, Kumaran K, Wahren J, Landau BR. 1991. Noninvasive tracing of Krebs cycle metabolism in liver. J Biol Chem 266:6975-6984.

Malloy CR, Sherry AD, Jeffrey FMH. 1988. Evaluation of carbon flux and substrate selection through alternate pathways involving the citric acid cycle of the heart by ${ }^{13} \mathrm{C}$ NMR spectroscopy. J Biol Chem 263:6964-6971.

Marshall BJ, Surveyor I. 1988. Carbon-14 urea breath test for the diagnosis of Campylobacter pylori associated gastritis. Clin Sci 29:11-16.

Marx A, de Graaf AA, Wiechert W, Eggeling L, Sahm H. 1996. Determination of the fluxes in the central metabolism of Corynebacterium glutamicum by nuclear magnetic resonance spectroscopy combined with metabolite balancing. Biotechnol Bioeng 49:111-129.

Narbad A, Hewlins MJE, Callely AG. 1989. ${ }^{13}$ C-NMR studies of acetate and methanol metabolism by methylotrophic Pseudomonas strains. J Gen Microbiol 135:1469-1477.

Novis BH, Gabay G, Leichtmann G, Peri M, Bernheim J, Pomeranz IS. 1991. Two-point analysis 15 -minute ${ }^{14} \mathrm{C}$-urea breath test for diagnosing Helicobacter pylori infection. Digestion 50:16-21.

Ormand JE, Talley NJ, Carpenter HA, Shorter RG, Conley CR, Wilson WR, DiMagno EP, Zinsmeister AR, Phillips SF. 1990. $\left[{ }^{14} \mathrm{C}\right]$ Urea breath test for diagnosis of Helicobacter pylori. Digest. Dis Sci 35:879-884.

Park SM, Klapa MI, Sinskey AJ, Stephanopoulos GN. 1999. Metabolite and isotopomer balancing in the analysis of metabolic cycles. Biotechn Bioeng 62:392-401.

Schmidt K, Carlsen M, Nielsen J, Villadsen J. (1997). Modeling isotopomer distributions in metabolic networks using isotopomer mapping matrices. Biotechnol Bioeng 55:831-840.

Schneider JF, Schoeller DA, Nemchausky B, Boyer JL, Klein P. 1978. Validation of ${ }^{13} \mathrm{CO}_{2}$ breath analysis as a measurement of demethylation of stable isotope labeled aminopyrine in man. Clin Chim Acta 84:153-162.

Shulman RG, Brown TR, Ugurbil K, Ogawa S, Cohen SM, den Hollander JA. 1979. Cellular applications of ${ }^{31} \mathrm{P}$ and ${ }^{13} \mathrm{C}$ nuclear magnetic resonance. Science 205:160-166.

Solomons NW, Schoeller DA, Wagonfeld JB, Ott D, Rosenberg IH, Klein PD. 1977. Application of a stable isotope $\left({ }^{13} \mathrm{C}\right)$-labeled glycocholate breath test to diagnosis of bacterial overgrowth and ileal function. $\mathrm{J}$ Lab Clin Med 90:431-439.

Sonntag K, Eggeling L, de Graaf AA, Sahm H. 1993. Flux partitioning in the split pathway of lysine synthesis in Corynebacterium glutami- 
cum—quantification by ${ }^{13} \mathrm{C}$ NMR and ${ }^{1} \mathrm{H}$ NMR spectroscopy. Eur J Biochem 213:1325-1331.

Szyperski T, Bailey JE, Wüthrich K. 1996. Detecting and dissecting metabolic fluxes using biosynthetic fractional C-13 labeling and twodimensional NMR spectroscopy. Trends Biotechnol 14:453-459.

Turner JM, Lawrence S, Fellows IW, Johnson I, Hill PG, Holmes GKT. 1987. $\left[{ }^{14} \mathrm{C}\right]$ Triolein absorption: A useful test in the diagnosis of malabsorption. Gut 28:694-700.

Walker TE, London RE. 1987. Biosynthetic preparation of L- $\left[{ }^{13} \mathrm{C}\right]-$ and $\left[{ }^{15} \mathrm{~N}\right]$ glutamate by Brevibacterium flavum. Appl Environ Microbiol 53:92-98.

Walsh K, Koshland DE. 1984. Determination of flux through the branch point of two metabolic cycles: The tricarboxylic acid cycle and the glyoxylate shunt. J Biol Chem 259:9646-9654.

Watkins JB, Klein PD, Schoeller DA, Kirschner BS, Park R, Perman JA. 1982. Diagnosis and differentiation of fat malabsorption in children using ${ }^{13} \mathrm{C}$-labeled lipids: Trioctanoin, triolein, and palmitic acid breath tests. Gastroenterology 82:911-917.

Watkins JB, Schoeller DA, Klein PD, Ott DG, Newcomer AD, Hofmann AF. 1977. $\left[{ }^{13} \mathrm{C}\right]$ Trioctanoin: A nonradioactive breath test to detect fat malabsorption. J Lab Clin Med 90:422-430.

Weinman EO, Strisower EH, Chaikoff IL. 1957. Conversion of fatty acids to carbohydrate: Application of isotopes to this problem and role of the Krebs cycle as a synthetic pathway. Physiol Rev 37:252-272. 